\title{
Genome Analysis and Development of a Multiplex TaqMan Real-Time PCR for Specific Identification and Detection of Clavibacter michiganensis subsp. nebraskensis
}

\author{
James T. Tambong, Renlin Xu, Fouad Daayf, Stephan Brière, Guillaume J. Bilodeau, Raymond Tropiano, Allison Hartke, \\ Lana M. Reid, Morgan Cott, Tammy Cote, and Irina Agarkova \\ First, second, and eighth authors: Ottawa Research and Development Centre, Agriculture and Agri-Food Canada, Ottawa, Ontario K1A 0C6, \\ Canada; third author: Department of Plant Science, University of Manitoba, Winnipeg, Manitoba, Canada; fourth, fifth, sixth, and seventh \\ authors: Canadian Food Inspection Agency, Ottawa, Ontario, Canada; ninth and tenth authors: Manitoba Corn Growers Association, Carman, \\ Manitoba, Canada; and eleventh author: Department of Plant Pathology, University of Nebraska, Lincoln. \\ Accepted for publication 14 July 2016.
}

\begin{abstract}
Tambong, J. T., Xu, R., Daayf, F., Brière, S., Bilodeau, G. J., Tropiano, R., Hartke, A., Reid, L. M., Cott, M., Cote, T., and Agarkova, I. 2016. Genome analysis and development of a multiplex TaqMan real-time PCR for specific identification and detection of Clavibacter michiganensis subsp. nebraskensis. Phytopathology 106:1473-1485.

The reemergence of the Goss's bacterial wilt and blight disease in corn in the United States and Canada has prompted investigative research to better understand the genome organization. In this study, we generated a draft genome sequence of Clavibacter michiganensis subsp. nebraskensis strain DOAB 395 and performed genome and proteome analysis of C. michiganensis subsp. nebraskensis strains isolated in 2014 (DOAB 397 and DOAB 395) compared with the type strain, NCPPB 2581 (isolated over 40 years ago). The

majority $(99.9 \%$ ) of the protein sequences had a 99.6 to $100 \%$ homology between C. michiganensis subsp. nebraskensis strains DOAB 395 and DOAB 397 , with only four protein sequences $(0.1 \%)$ exhibiting a similarity $<70 \%$. In contrast, $3.0 \%$ of the protein sequences of strain DOAB 395 or DOAB 397 showed low homologies $(<70 \%)$ with the type strain NCPPB 2581. The genome data were exploited for the development of a multiplex TaqMan real-time polymerase chain reaction (PCR) tool for rapid detection of $C$. michiganensis subsp. nebraskensis. The specificity of the assay was validated using 122 strains of Clavibacter and non-Clavibacter spp. A blind test and naturally infected leaf samples were used to confirm specificity. The sensitivity ( 0.1 to $1.0 \mathrm{pg}$ ) compared favorably with previously reported realtime PCR assays. This tool should fill the current gap for a reliable diagnostic technique.
\end{abstract} proteomes of strains DOAB 395 and DOAB 397 exhibited a 99.2\% homology but had 92.1 and $91.8 \%$ homology, respectively, with strain NCPPB 2581 . The
Additional keywords: pseudogenes, stacking energy.
Clavibacter michiganensis is a gram-positive bacterium (family Microbacteriaceae Park et al. 1995 emend. Zhi et al. 2009) comprising five core subspecies, all of which are phytopathogens on specific important agricultural crops worldwide. The cells are rods of coryneform morphology. The cell wall contains B2 $\gamma$-type peptidoglycan with the diaminobutyric acid MK-9 as the predominant menaquinone, and phosphatidyglycerol and diphosphatidyglycerol as the basic polar lipids (Agarkova et al. 2011; Davis et al. 1984). The genomes have a high GC content of 72 to $74 \mathrm{~mol} \%$ (Agarkova et al. 2011; Davis et al. 1984; Tambong et al. 2015). Four of these subspecies are classified as quarantine organisms due to the high economic threat they pose (Jacques et al. 2012). C. michiganensis subsp. michiganensis causes bacterial wilt and canker of tomato (Solanum lycopersicum)(Anonymous 2005), whereas C. michiganensis subsp. sepedonicus causes diseases on potato. C. michiganensis subsp. insidiosus is a pathogen of alfalfa, C. michiganensis subsp. tessellarius is pathogenic to wheat, and $C$. michiganensis subsp. nebraskensis infects corn. All subspecies seem to be able to invade seed, show only poor survival capabilities in soil (Davis et al. 1984), and may have an epiphytic lifestyle (Ahmad et al. 2015).

Corresponding author: J. T. Tambong; E-mail address: james.tambong@agr.gc.ca

*The $\boldsymbol{e}$-Xtra logo stands for "electronic extra" and indicates that one supplementary table and five supplementary figures are published online.

http://dx.doi.org/10.1094/PHYTO-05-16-0188-R

(C) Her Majesty the Queen in Right of Canada, as represented by the Minister of Agriculture and Agri-Food Canada, 2016
The reemergence and rapid spread of the Goss's bacterial wilt and blight disease in the United States and Canada has prompted investigative research to better understand the pathogen. C. michiganensis subsp. nebraskensis is the causal agent of the Goss's bacterial wilt and blight of corn or maize (Zea mays L.). The disease was first reported in 1969 in south-central Nebraska and neighboring states (Vidaver et al. 1981) but, in recent years, it has been confirmed in Minnesota, Wisconsin, Kansas, Colorado, Wyoming, South Dakota, Iowa, Illinois, Wisconsin, Texas, Indiana, and Canada(Agarkova et al. 2011; Dawson 2010; Heppner 2010; Jackson et al. 2007; Malvick et al. 2010; Ruhl et al. 2009; Tambong et al. 2015). Yield losses can be as high as $50 \%$ from systemic infections of the xylem (Eichenlaub et al. 2006; Vidaver et al. 1981). Such infections may be latent, without visible symptoms (Davis et al. 1984; Tambong et al. 2015). In addition, leaf symptoms may be confused with the disease of Stewart's wilt on corn caused by Pantoea stewartii subsp. stewartii. No characteristic symptoms of Goss's wilt are visible on seed. Based on these factors, Paul and Smith (1989) proposed that C. michiganensis subsp. nebraskensis is a candidate A1 quarantine organism. This attribute indicates potential regulatory challenges because export countries will be required to certify shipments destined to regions with no recent reports of the disease.

Unlike $C$. michiganensis subspp. michiganensis and sepedonicus, the genome organization of $C$. michiganensis subsp. nebraskensis is not well understood and the molecular mechanisms of its pathogenicity are unknown (Agarkova et al. 2011). Rapid expansion of nucleotide sequencing capacity with next-generation sequencing technology provides an opportunity to study C. michiganensis subsp. nebraskensis genomes and identify changes in chromosomal virulence 
factors. Recently, the complete genome of the type strain (NCPPB 2581) of C. michiganensis subsp. nebraskensis was deposited in GenBank (HE614873) while Tambong et al. (2015) published the draft genome of strain DOAB 397 that was isolated in 2014 in the province of Manitoba, Canada. Preliminary analysis of these two genomes suggested that potential differences exist between $C$. michiganensis subsp. nebraskensis strain DOAB 397 and the type strain (NCPPB 2581). In addition, strain DOAB 397 showed significantly higher pathogenicity than the strain NCPPB 2581 on two Manitoban corn cultivars (F. Daayf, unpublished). In-depth analysis may show differences in the genome organization.

There are no standardized traditional techniques for the detection and identification of the Goss's wilt pathogen and certification of corn or maize seed. An enzyme-linked C. michiganensis subsp. michiganensis ImmunoStrip assay developed by Agdia Inc. is recommended with caution for detection of $C$. michiganensis subsp. nebraskensis due to strong positive reactions with four isolates of Ochrobactrum and Microbacterium spp. (https://d163axztg8am2h. cloudfront.net/static/doc/81/62/5500cccb797e0661761c277f968e. pdf). This creates some degree of uncertainty in $C$. michiganensis subsp. nebraskensis identification or detection with potential economic impact. Nevertheless, it is inexpensive and easy to use in the field. Polymerase chain reaction (PCR)-based methods would allow for a rapid and more reliable detection of the pathogen on corn plant tissues and identification of the pure cultures; however, very few PCR-based techniques are publicly available. Waleron et al. (2011) reported the use of specific random fragment length polymorphism patterns to differentiate $C$. michiganensis subspecies. Also, R. R. McNally, C. A. Ishimaru, and D. K. Malvick (unpublished data) reported a PCR-mediated assay using primers derived from a predicted gene while Feng et al. (2014) developed a nested-PCR using the 16S-23S intergenic transcribed spacer (ITS). Conventional PCR-based techniques used to date require post-PCR handling to visualize the results and, as such, are prone to errors.

Real-time PCR provides a better alternative for accurate detection and identification of specific plant pathogens (Tambong et al. 2008; Xu and Tambong 2011). TaqMan real-time PCR relies on the combination of a primer set and an additional dual-labeled fluorogenic probe to allow continuous monitoring of amplicon synthesis during thermocycling (Orlando et al. 1998). Because postPCR processing steps are not required, the assay can be easily automated, leading to high sample throughput (Weller et al. 2000). Yasuhara-Bell et al. (2016) reported a loop-mediated PCR amplification system for detection of $C$. michiganensis subsp. nebraskensis in maize targeting the tripartite ATP-independent periplasmic-type C4-dicarboxylate transport system large permease component, while Bach et al. (2003) reported a TaqMan-PCR protocol for quantification and differentiation of $C$. michiganensis subspecies targeting 16S-23S ITS. Single-gene-probe real-time PCR have an inherent disadvantage of not having a confirmatory second probe.

The objectives of this study were to (i) generate and analyze the structural DNA atlas of the complete genome of type strain C. michiganensis subsp. nebraskensis NCPPB 2581, (ii) sequence and assemble a second-draft genome of a recent $C$. michiganensis subsp. nebraskensis strain DOAB 395, (iii) perform genome or proteome analysis of $C$. michiganensis subsp. nebraskensis strains isolated in 2014 (DOAB 397 and DOAB 395) compared with the type strain (NCPPB 2581) isolated over 40 years ago to provide an insight into any differences in their organization, and (iv) develop and validate a multiplex TaqMan real-time PCR assay targeting a secreted cellulase (CMN_02390) and 50S ribosomal protein L36 (syn. rpsJ) for reliable detection and identification of $C$. michiganensis subsp. nebraskensis in pure cultures and naturally infected corn leaves. The secreted cellulase gene is a functional endoglucanase with an ortholog in C. michiganensis subsp. michiganensis (CMM_2443) and $C$. michiganensis subsp. sepedonicus (CMS_0045). The C. michiganensis subsp. michiganensis ortholog is the celB gene, a putative secreted cellulase containing cellulose-binding domain
(Gartemann et al. 2008). In addition, the assay uses a $\lambda$ DNAderived internal control probe (Tambong et al. 2008) used to test for the presence of PCR inhibitors across DNA samples. Finally, the multiplex TaqMan assay was evaluated across frequently used realtime PCR platforms.

\section{MATERIALS AND METHODS}

Bacterial strains and DNA extraction. In total, 122 bacterial strains from various sources were used in this study (Table 1). Isolation of $C$. michiganensis subsp. nebraskensis strains was done using the Corynebacterium nebraskense semiselective medium (Gross and Vidaver 1978). Strains of Pectobacterium spp. were cultured in tryptone yeast extract liquid media while $C$. michiganensis subspecies were grown in nutrient broth supplemented with yeast extract (Smid et al. 1995). All other bacterial strains were grown using Luria-Bertani (tryptone at $10 \mathrm{~g} \mathrm{liter}^{-1}$, yeast extract at $5 \mathrm{~g} \mathrm{liter}^{-1}$, and $\mathrm{NaCl}$ at $10 \mathrm{~g} \mathrm{liter}^{-1}$ ) or nutrient broth media. Stock bacterial cultures were maintained on the same medium supplemented with $25 \%$ (wt/vol) glycerol at $-80^{\circ} \mathrm{C}$. Genomic DNA was purified using the Wizard SV Genomic DNA purification system (Promega Corp.). The concentration of DNA was determined using the NanoDrop ND-1000 Spectrophotometer (NanoDrop Technologies). Purified DNA was stored at $-20^{\circ} \mathrm{C}$.

$16 S$ ribosomal RNA gene amplification and sequencing. The primer pair $16 \mathrm{~S} 27$ (5'-AGAGTTTGATCMTGGCTCAG-3') and 1482R (5'-TACGGYTACCTTGTTACGACTT-3') (Lane 1991), was used. Primers were synthesized by Invitrogen Inc., and PCR amplifications were performed in a $10-\mu$ l volume reaction using a thermal cycler (Biometra) with $10 \mathrm{ng}$ of bacterial DNA $(1 \mu \mathrm{l}), 1 \mu \mathrm{l}$ of $10 \times$ PCR buffer, $0.75 \mu \mathrm{l}$ of $2 \mathrm{mM}$ deoxynucleoside triphosphates (dNTP), $0.08 \mu \mathrm{l}$ of each primer $(20 \mu \mathrm{M}), 0.1 \mu \mathrm{l}$ of Titanium Taq DNA polymerase $(5 \mathrm{U} / \mu \mathrm{l}$; BD/Biosciences/Clontech), and $6.99 \mu \mathrm{l}$ of MilliQ water. Optimal PCR conditions included an initial denaturation of $95^{\circ} \mathrm{C}$ for $5 \mathrm{~min}$; followed by 40 cycles of $95^{\circ} \mathrm{C}$ for $45 \mathrm{~s}, 62^{\circ} \mathrm{C}$ for $45 \mathrm{~s}$, and $72^{\circ} \mathrm{C}$ for $90 \mathrm{~s}$; and a final extension at $72^{\circ} \mathrm{C}$ for $10 \mathrm{~min}$. Sequencing was done using ABI BigDye Terminator chemistry v3.1 (Applied Biosystems) and run on an ABI 3130xl automated sequencer (Applied Biosytems/Hitachi).

Also, the identity of strains exhibiting a positive TaqMan realtime PCR reaction were validated by sequencing three ribosomal protein gene (rpsB, rps $\mathrm{G}$, and $r p m \mathrm{~F}$ ) fragments followed by Basic Local Alignment Tool (BLAST) analysis. Primer sequences of the ribosomal gene fragments are given in Table 2. PCR amplification was performed as described above at an annealing temperature of $70^{\circ} \mathrm{C}$ and sequencing was done as described above.

Genome downloads. Whole- and draft-genome data from eight strains-C. michiganensis subsp. sepedonicus ATCC 33113 (AM849034), C. michiganensis subsp. michiganensis NCPPB 382 (AM711867), C. michiganensis subsp. nebraskensis NCPPB 2581 (HE614873), C. michiganensis subsp. insidiosus R1-1 (CP011043), C. michiganensis subsp. nebraskensis DOAB 397 (LAKL00000000), C. michiganensis subsp. tessellarius DOAB 609 (LQXA00000000), C. michiganensis CF11 (JROD00000000), and C. michiganensis LMG 26808 (AZQZ00000000)—representing the $C$. michiganensis subspecies were downloaded from the GenBank database (Benson et al. 2012) at the National Center for Biotechnology Information (NCBI, http://www.ncbi.nlm.nih.gov/genome/). NCBI GenBank International Nucleotide Sequence Database Collaboration or whole-genome-sequence (WGS) numbers were used to download each genome in the NCBI GenBank format, using the getgbk.pl script as implemented in CMG-Biotools (Vesth et al. 2013). DNA sequences were extracted from GenBank files and saved in FASTA format using the saco_convert script (Jensen and Knudsen 2000).

de novo sequencing of $\boldsymbol{C}$. michiganensis subsp. nebraskensis strain DOAB 395. Preliminary analysis of the genome of a recent (2014) C. michiganensis subsp. nebraskensis strain and the type strain isolated over 40 years ago indicated potential differences (Tambong 
TABLE 1. Bacteria used to evaluate the specificity of the real-time polymerase chain reaction (PCR) assay, TaqMan detection data, and BLAST results of ribosomal proteins of positive strains

\begin{tabular}{|c|c|c|c|c|c|c|c|c|}
\hline \multirow[b]{2}{*}{ Bacterial species, strain } & \multirow[b]{2}{*}{ Yearc $^{c}$} & \multirow[b]{2}{*}{ AFLPd $^{d}$} & \multirow[b]{2}{*}{$16 \mathrm{~S} \mathrm{rRNA}^{\mathrm{e}}$} & \multicolumn{3}{|c|}{ BLAST results $^{\mathrm{a}}$} & \multicolumn{2}{|c|}{$\begin{array}{l}\text { TaqMan real-time } \\
\text { PCR reaction }\end{array}$} \\
\hline & & & & $r p s \mathrm{~B}$ & $r p s \mathrm{G}$ & $\operatorname{rpmF}$ & cell_cmn38pb & cmn_rpsJ27pb \\
\hline \multicolumn{9}{|l|}{ Clavibacter michiganensis subsp. nebraskensis } \\
\hline CN18-5, CN18-6, CN38-1 & 1970 & A1 & Clavibacter & + & + & + & + & + \\
\hline CN298, NCPPB 2581 & 1971 & A1 & Clavibacter & + & + & + & + & + \\
\hline $\mathrm{CN} 30-1$ & 1972 & A1 & Clavibacter & + & + & + & + & + \\
\hline CN49-2, CN62-1 & 1975 & A1 & Clavibacter & + & + & + & + & + \\
\hline $1994 \mathrm{NC}+$ & 1994 & A1 & Clavibacter & + & + & + & + & + \\
\hline 1996 CIBA, 1996 NC+, 1996 Pioneer & 1996 & A1 & Clavibacter & + & + & + & + & + \\
\hline 9918-1, 9918-3, 9910 & 1999 & A1 & Clavibacter & + & + & + & + & + \\
\hline 20032, 20037 & 2003 & A1 & Clavibacter & + & + & + & + & + \\
\hline 31341,32719 & 2004 & A1 & Clavibacter & + & + & + & + & + \\
\hline K293E, 313.2 PDG101 & 1971 & $\mathrm{~A} 2$ & Clavibacter & + & + & + & + & + \\
\hline CNK-2 & 1972 & A2 & Clavibacter & + & + & + & + & + \\
\hline $\mathrm{CN} 4-1, \mathrm{CN} 81-2$ & 1973 & A2 & Clavibacter & + & + & + & + & + \\
\hline CN72-1 & 1974 & A2 & Clavibacter & + & + & + & + & + \\
\hline CN68-1, CN76-2 & 1975 & $\mathrm{~A} 2$ & Clavibacter & + & + & + & + & + \\
\hline \multicolumn{9}{|l|}{ CN72-10, CN72-11A, CN72-23A, CN72-25A, } \\
\hline CN72-28, CN72-29 & 1982 & A2 & Clavibacter & + & + & + & + & + \\
\hline $200717-\mathrm{C}$ & 2007 & $\mathrm{~A} 2$ & Clavibacter & + & + & + & + & + \\
\hline Butcher (G2) & 2008 & A2 & Clavibacter & + & + & + & + & + \\
\hline 200900798 Texas & 2009 & $\mathrm{~A} 2$ & Clavibacter & + & + & + & + & + \\
\hline $\begin{array}{l}\text { DOAB 391, DOAB392, DOAB393, DOAB 395, } \\
\text { DOAB 396, DOAB 397, DOAB 398, DOAB } 399, \\
\text { DOAB 400, DOAB 401, DOAB 402 }\end{array}$ & 2014 & nd & Clavibacter & + & + & + & + & + \\
\hline \multicolumn{9}{|l|}{ DOAB 799, DOAB 800, DOAB 802, DOAB 803, DOAB } \\
\hline \multicolumn{9}{|l|}{ Other bacterial species } \\
\hline $\begin{array}{l}\text { Pantoea stewartii: LMG } 2632^{\mathrm{T}}, \text { LMG } 2715^{\mathrm{T}} \text {, } \\
\text { DOAB } 21, \text { DOAB } 22\end{array}$ & $\begin{array}{l}\text { 1970, 1970, } \\
2006,2006\end{array}$ & $\mathrm{n} / \mathrm{a}$ & Pantoea & - & - & - & - & - \\
\hline P. ananatis: LMG $2665^{\mathrm{T}}, \mathrm{LMG} 2667$ & 1966,1958 & & Pantoea & - & - & - & - & - \\
\hline P. allii: LMG 24248 & 2005 & $\mathrm{n} / \mathrm{a}$ & Pantoea & - & - & _- & - & - \\
\hline P. eucalypti: LMG $24197^{\mathrm{T}}$, LMG 24198 & 2004,2004 & $\mathrm{n} / \mathrm{a}$ & Pantoea & - & - & - & - & - \\
\hline Dickeya dadantii: EC46, GSPB 413 & UNK & $\mathrm{n} / \mathrm{a}$ & Pantoea & - & - & - & - & - \\
\hline P. agglomerans: LMG $1286^{\mathrm{T}}$, LMG 2102 & 1920, UNK & & Pantoea & - & - & - & - & - \\
\hline Pseudomonas syringae: Psgly-2, HBA2, T1 & UNK & $\mathrm{n} / \mathrm{a}$ & Pseudomonas & - & - & - & - & - \\
\hline \multicolumn{9}{|l|}{ Xanthomonas campestris var. phaseoli: ATCC 10199 , } \\
\hline ATCC 1019315, XCC007 & UNK & $\mathrm{n} / \mathrm{a}$ & Xanthomonas & - & - & - & - & - \\
\hline Pectobacterium carotovorum: ECC71, Eca9204t & UNK & $\mathrm{n} / \mathrm{a}$ & Pectobacterium & - & - & - & - & - \\
\hline Pseudomonas fluorescens: LMG 1794, pf-5 & 1951,1979 & $\mathrm{n} / \mathrm{a}$ & Pseudomonas & - & - & - & - & - \\
\hline Bacillus subtilis: $\mathrm{CH} 10, \mathrm{Ch} 15$ & 2007 & & Bacillus & - & - & - & - & - \\
\hline Streptomyces scabies: CG1 & UNK & $\mathrm{n} / \mathrm{a}$ & Streptomyces & - & - & - & - & - \\
\hline S. acidiscabies: ATCC49003 & UNK & $\mathrm{n} / \mathrm{a}$ & Streptomyces & _- & _- & - & _- & _- \\
\hline S. eauropeascabies: CFPB 4497 & 1986 & $\mathrm{n} / \mathrm{a}$ & Streptomyces & - & - & - & - & - \\
\hline
\end{tabular}

a $r p s \mathrm{~B}, r p s \mathrm{G}$, and $r p m \mathrm{~F}$ were sequenced and BLAST performed for strains showing positive TaqMan detection. Positive (+) BLAST results indicates a hit to C. michiganensis subsp. nebraskensis NCPPB 2581 genome (HE614873) with 100\% homology while a negative sign (-) indicates no hits or PCR amplification using the respective rps primers. n/a, not applicable; nd, not determined.

b Symbols: + indicates positive reaction based on detectable fluorescence (with mean threshold values between 19 and 22) and - indicates no detectable fluorescence. C. michiganensis subsp. nebraskensis strains from 1969 to 2009 were kindly provided by Dr. Anne Vidaver (University of Nebraska-Lincoln). Other strains were obtained from culture collections: LMG, Belgian Coordinated Collections of Microorganisms/Laboratory of Microbiology; ATCC, American Type Culture Collection; CFPB, French Culture Collection for Plant Associated bacteria; GSPB: Göttingen Collection of Phytopathogenic Bacteria. Streptomyces scabies strain CG1 was kindly provided by Carol Beaulieu (Université de Sherbrooke, Quebec, Canada). Strains with prefix DOAB were isolated from infected corn leaves in Manitoba, Canada.

c Year of isolation; UNK = unknown.

d Composite amplified fragment length polymorphism (AFLP)-BOX grouping of C. michiganensis subsp. nebraskensis strains according to Agarkova et al. (2011); nd $=$ not done and $\mathrm{n} / \mathrm{a}=$ not applicable.

e $16 \mathrm{~S}$ rRNA identification. 
et al. 2015). To confirm these differences, a second strain isolated in 2014 was sequenced. Genomic DNA shearing, library preparation, and the whole-genome shotgun sequence of $C$. michiganensis subsp. nebraskensis DOAB 397 were performed by the Génome-Québec Innovation Centre. The draft genome was determined by paired-end sequencing using Illumina MiSeq technology (Génome-Québec). In total, 1,347,336 paired-end reads, each 250 bp in length, totaling $336,834,000 \mathrm{bp}$, were obtained. The quality of the reads was checked by using FastQC version 0.11.3 (Andrews 2015). De novo assembly was performed using ABySS version 1.5.2 (Simpson et al. 2009) at different k-mer values (75 to 113). Scaffolds with length $<300 \mathrm{bp}$ were discarded. A k-mer value of 89 gave the best assembly quality (no misassembled scaffolds) based on QUAST version 2.3 (Gurevich et al. 2013). The 25 scaffolds of $C$. michiganensis subsp. nebraskensis DOAB 397 were ordered and oriented using the CAR software ( $\mathrm{Lu}$ et al. 2014) based on the complete genome sequence of the type strain, C. michiganensis subsp. nebraskensis NCPPB 2581 (NC_020891). Contigs were annotated using the NCBI Prokaryotic Genome Automatic Annotation Pipeline (PGAAP) (Angiuoli et al. 2008) with the best-placed reference protein set. The assembled contigs were deposited into the GenBank WGS database with accession number LSOE00000000.

Structural DNA atlases. The structural DNA atlas of the complete genome of the type strain, NCPPB 2581, was done using CMG-Biotools (Vesth et al. 2013), and a brief description is given below. A numerical value was calculated for each nucleotide in the genome sequence and saved in a file read by GeneWiz. This program calculates the average and standard deviation of percent AT, GC skew, global repeats, intrinsic curvature, and stacking energy. The window is maximally colored if the average value of the window is more than three standard deviations on either side of the overall average. GC skew, which is calculated as $[(\mathrm{G}-\mathrm{C}) /(\mathrm{G}+\mathrm{C})]$, is required for determining the origin and terminus of replication (Lobry 1996; Worning et al. 2006). Intrinsic curvature, calculated using CURVATURE (Bolshoy et al. 1991; Shpigelman et al. 1993), is a measure of DNA curvature, and the dinucleotide values provided are used to compute the stacking energy (Ornstein and Rein 1978). Global repeats represent sequences present in at least two copies in the genome. Each of the parameters is computed independently through a pipeline and outputted in a circular plot (Vesth et al. 2013). The gene annotations are obtained from GenBank files containing the coding regions. Atlases were not generated from the draft genomes of $C$. michiganensis subsp. nebraskensis strains DOAB 395 and DOAB 397 because a genome atlas can only be visualized from one single replicon but not from a multifasta file such as draft genomes.

Proteome comparisons using BLAST. For protein-annotated genomes (AM849034, AM711867, CP011043, HE614873, and AZQZ00000000) or draft genomes, gene and protein extractions were done as previously described (Jensen and Knudsen 2000; Vesth et al. 2013) using the saco_extract script or the gene-finding program Prodigal (Hyatt et al. 2010; Vesth et al. 2013). Proteome comparisons were done using the program blastmatrix (Vesth et al. 2013) and pairwise proteome comparisons were performed with BLAST (Binnewies et al. 2005) to generate a BLAST matrix. Protein sequences were compared with each other. Two sequences are similar and collected in one "protein family" if the BLAST hit had 50\% identical matches in the alignment and the length of the alignment is $50 \%$ of the longest gene in the comparison. For the comparison of two genomes, protein families are built through single linkage. Paralogs within a proteome are also evaluated and outputted at the bottom row of the matrix (Vesth et al. 2013).

Also, the pan- and core-genome plot was also used to compare proteomes (using the 50/50 cut-off, as described above). The program (pancoreplot) produces a plot and a table which can be used to look up the underlying values of the plot (Vesth et al. 2013). The pan-genome is the entire set of protein families from all genomes in the comparison while the core-genome consists of protein families with representatives found in all investigated genomes. Using the pancoreplot_tree command (Vesth et al. 2013), a pan-genome phylogenetic tree was created based on the shared gene families as defined in the pan- and core-genome analysis.

Identification of genomic Islands. IslandViewer 3 (http:// www.pathogenomics.sfu.ca/islandviewer/) was used to predict and analyze genomic islands (GI) (Dhillon et al. 2015). This program uses the most precise version of the resistance gene identifier (RGI) method for identifying genes involved in antimicrobial resistance

TABLE 2. Oligonucleotide primers, probes, approximate amplicon length, and their locations on Clavibacter michiganensis subsp. nebraskensis genome sequence (HE614873)

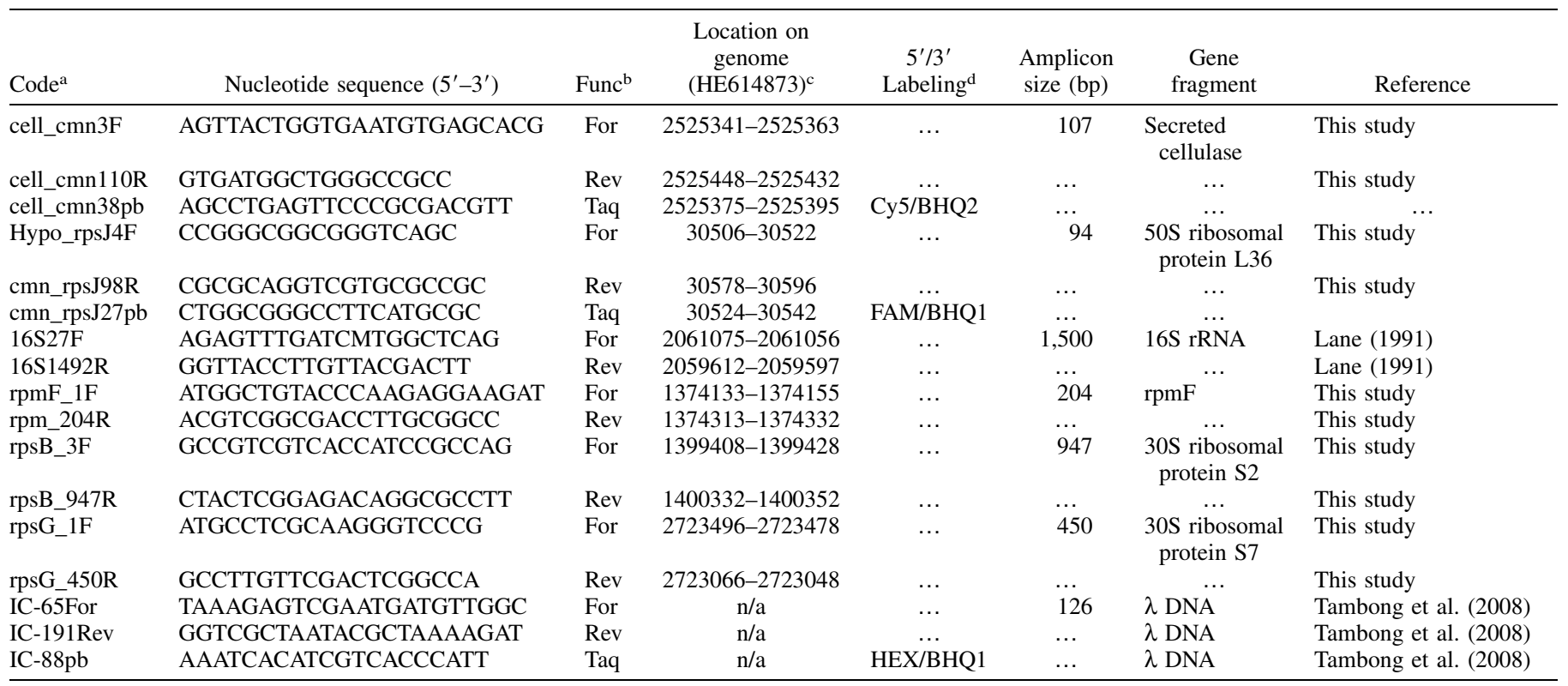

a Oligonucleotide code.

${ }^{\mathrm{b}}$ Function: For $=$ forward primer, Rev $=$ reverse primer, and Taq $=$ TaqMan probe.

${ }^{c}$ Reporter dye labeling under multiplex conditions.

d Abbreviation: $\mathrm{n} / \mathrm{a}=$ not applicable. 
(AMR) (McArthur et al. 2013). The RGI uses a BLASTp search against the set of curated resistance genes in the Comprehensive Antibiotic Resistance Database (https://card.mcmaster.ca/) with precise filtering criteria based on different types of resistance classes. The analysis of pathogen-associated genes (PAG) was performed as reported by Ho Sui et al. (2009) and implemented in IslandViewer 3 (Dhillon et al. 2015). GI identification on the draft genome of C. michiganensis subsp. nebraskensis DOAB 395 was performed using the complete genome of $C$. michiganensis subsp. nebraskensis strain NCPPB 2581 as a reference, as recommended by Dhillon et al. (2015).

Primers and TaqMan probe design and real-time PCR conditions. Using comparative genomics data, the genes $c e l \mathrm{~B}$ and rps J were identified as candidates for TaqMan probes based on nucleotide variation across the $C$. michiganensis subspecies. The $c e l \mathrm{~B}$ and $r p s \mathrm{~J}$ sequences of all the subspecies were downloaded or extracted from GenBank and aligned in MegAlign (version 7.0; DNASTAR). Specific primers and dual-labeled probes were designed as previously reported (Tambong et al. 2008; Xu and Tambong 2011). A similarity search was performed using the Blastn (nucleotide versus nucleotide comparison) with the primers as queries against all publicly available GenBank database, as previously described (Tambong et al.2006). The location of the primers and probes on the C. michiganensis subsp. nebraskensis genome (HE614873), nucleotide sequences, melting temperatures, and other characteristics are shown in Table 2. The primers and probe were designed and analyzed for dimer or hairpin loop structures by using oligo 6.71 software (Molecular Biology Insights). Primers and probes were synthesized by Sigma-Aldrich and labeled with the corresponding fluorescent reporter dyes covalently coupled to the $5^{\prime}$ end and with quencher at the $3^{\prime}$ end (Table 2).

Initial TaqMan real-time PCR was conducted in a Chromo4 realtime PCR System (MJ Research Bio-Rad Laboratories). PCR was performed by using $5 \mu \mathrm{l}$ of $2 \times$ SsoAdvanced Universal Probes Supermix (Bio-Rad Laboratories), $0.2 \mu \mathrm{l}$ of each primer at $20 \mu \mathrm{mol}$ liter $^{-1}$ and probe at $10 \mu \mathrm{mol}$ liter $^{-1}, 1 \mu \mathrm{l}$ of template or standard
DNA, and $3.4 \mu \mathrm{l}$ of sterile ultrapure water to a total reaction volume of $10 \mu \mathrm{l}$. The thermal cycling optimized conditions were an initial denaturation at $95^{\circ} \mathrm{C}$ for $15 \mathrm{~min}$ followed by 50 cycles at $95^{\circ} \mathrm{C}$ for $1 \mathrm{~s}$ and $60^{\circ} \mathrm{C}$ for $1 \mathrm{~min}$. Detection and quantification of the fluorescence was read after every cycle and data were assembled using Opticon analysis software (version 3.1; MJ Research/Bio-Rad Laboratories). Triplicates of standards and samples were subjected simultaneously to real-time PCR analysis, with each run including a negative control (no DNA template).

Sensitivity and specificity. The detection limit (sensitivity) of the assay was determined using purified genomic DNA of C. michiganensis subsp. nebraskensis strain NCPPB 2581 (type strain). The DNA was serially diluted 10 -fold from $10 \mathrm{ng}$ to $1 \mathrm{fg}$ in PCR water (Thermo Scientific) and subjected to TaqMan PCR amplification using the corresponding probes and primers. All reactions were performed in triplicate.

Specificity of the assay was evaluated on genomic DNA of 122 strains, including C. michiganensis subsp. nebraskensis $(n=82)$ and closely $(n=12)$ and distantly $(n=28)$ related bacterial species (Table 1). The $C$. michiganensis subsp. nebraskensis strains used were isolated between 1972 and 2015. The DNA for all the strains was diluted to $1 \mathrm{ng}^{-1} \mathrm{l}^{-1}$ and TaqMan real-time PCR was performed using the same conditions indicated above. Each strain was run in duplicate and repeated once. DNA samples that did not show detectable fluorescent signals were evaluated for PCR inhibition using the IC-65for/IC-65rev primer pair with the hex-labeled probe (IC-88pb), as previously described (Tambong et al. 2008).

Comparing real-time PCR platforms. The compatibility of the multiplex assay across three widely used real-time PCR platforms was evaluated using the Chromo4 System (MJ Research Bio-Rad Laboratories), LightCycler 480 instrument (Roche), and CFX96 Detection System (Bio-Rad Laboratories). The assay used three probes (cell_cmn38pb, cmn_rps27pb, and IC-88pb) labeled with Cy5, 6FAM, and hex reporter dyes, respectively, in a multiplex run in a $25-\mu 1$ total volume. The sensitivity using dilutions ( $1 \mathrm{ng}$ to $1 \mathrm{fg}$ ) of the DNA of NCPPB 2581 and the

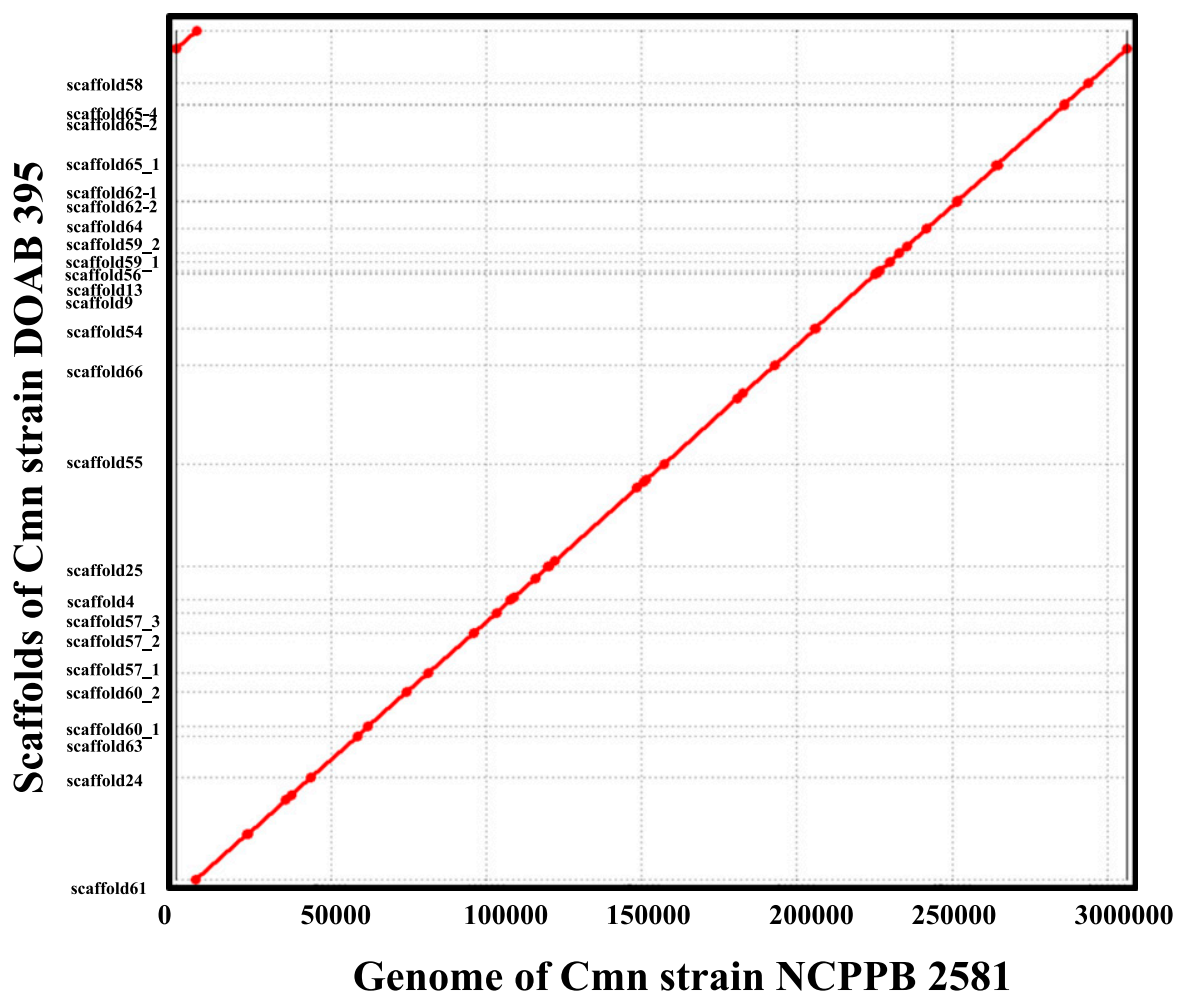

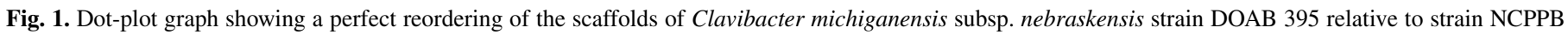
2581. Graph was created by the program CAR (Lu et al. 2014). 
specificity of the different instruments were evaluated using 15 strains, consisting of $C$. michiganensis subsp. nebraskensis $(n=6)$, other $C$. michiganensis subspecies $(n=4)$, and distantly related bacterial species $(n=2)$ in triplicate. The PCR conditions were as described above.

Detection of $C$. michiganensis subsp. nebraskensis in corn leaf samples by TaqMan real-time PCR. Validation of the assay was done using growth-chamber-inoculated plants in a blind test and naturally infected corn plants collected in 2014 and 2015. The growth-chamber inoculations of eight plants were performed by the Canadian Food Inspection Agency (CFIA). After inoculations, leaves were harvested, dried, coded for blind testing, and sent to the Bacteriology Laboratory of Agriculture and Agri-Food Canada for processing and detection. Also, 25 field-infected leaves were collected in Manitoba and shipped to the Bacteriology Lab for processing. Total DNA was extracted from leaf samples $(200 \mathrm{mg})$ with Ultraclean soil DNA isolation kits (Mo Bio Laboratories) following the manufacturer's protocol. The DNA quality was verified by electrophoresis on a $1.0 \%$ agarose gel and the concentration was determined using the Nano-Drop ND-1000 Spectrophotometer (NanoDrop Technologies). The presence of PCR inhibition was evaluated using the IC-65for/IC-65rev primer pair with the hex-labeled probe (IC-88pb), as previously described
(Tambong et al. 2008). Real-time PCR detection was performed on the DNA as indicated above. To confirm the presence of $C$. michiganensis subsp. nebraskensis in field samples, plate isolation was performed using a semiselective medium, as previously described (Gross and Vidaver 1978). Five peach-colored bacterial colonies were removed from agar and suspended in $20 \mu \mathrm{l}$ of autoclaved milliQ water and colony PCR was performed for $16 \mathrm{~S}$ ribosomal RNA (rRNA). The generated amplicons were sequenced as indicated above. A BLAST search was performed with the nucleotide sequences for genus-level identification.

\section{RESULTS}

Summary statistics of $C$. michiganensis subsp. nebraskensis strain DOAB 395 draft genome. The draft genome comprised 25 scaffolds (minimum, 2,814 bp; maximum, 373,300 bp; $\mathrm{N}_{50}$, $197,574 \mathrm{bp}$; total size, $3,077,355 \mathrm{bp}$ ). The quality of the draft genome of DOAB 395 was good because no misassembled fragments were detected using Quast software (Gurevich et al. 2013), and the dot-plot graph of scaffolds reordering against the complete strain NCPPB 2581 showed an almost perfect alignment (Fig. 1). The $\mathrm{G}+\mathrm{C}$ content of the draft genome is $72.6 \%$, with an

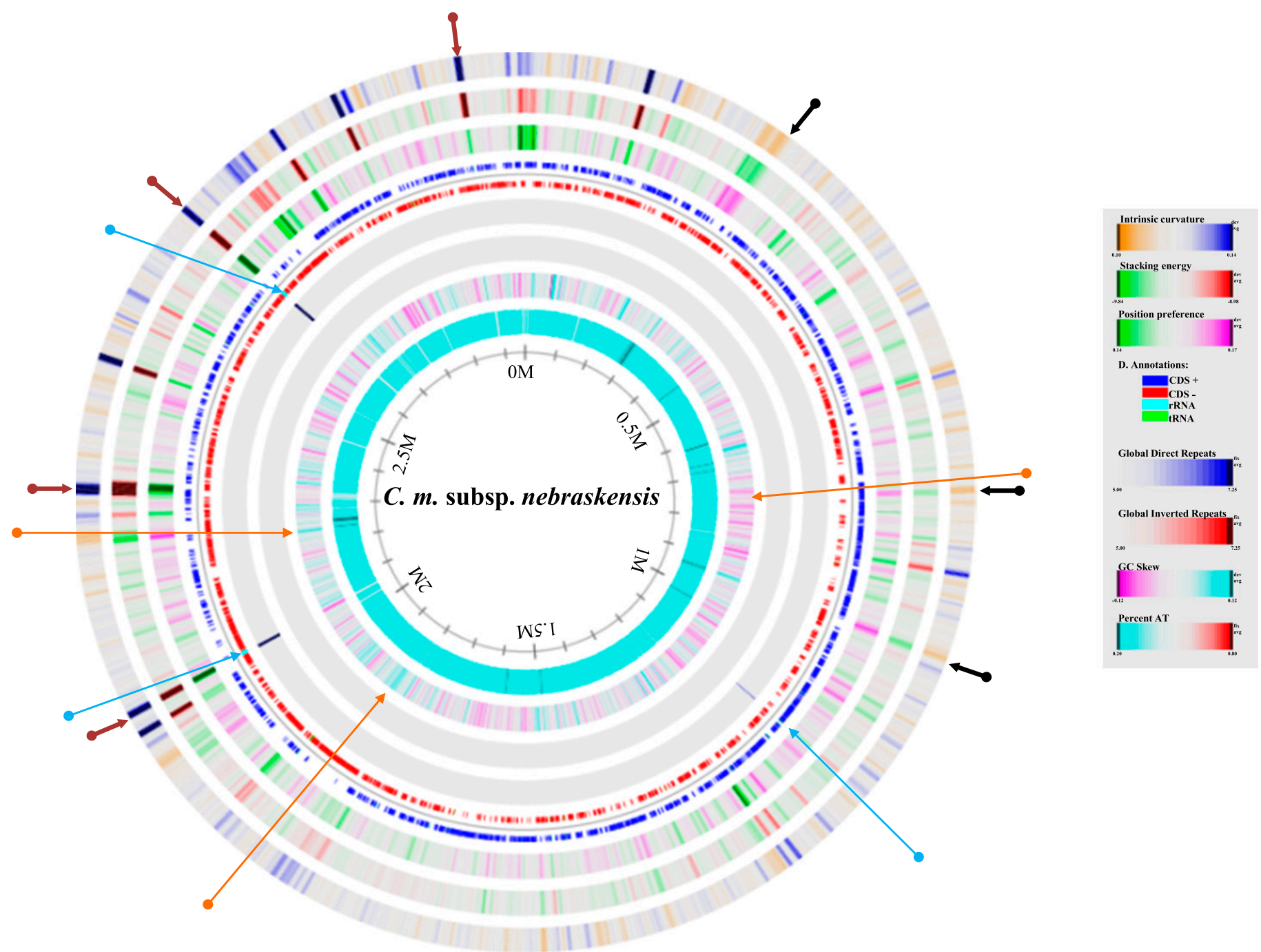

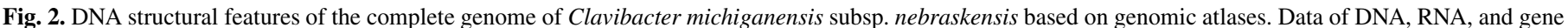

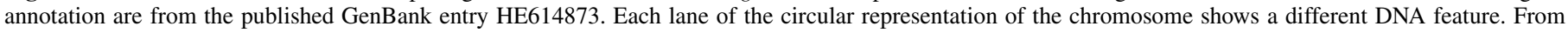

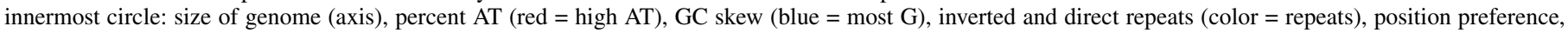

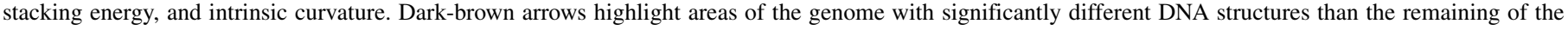

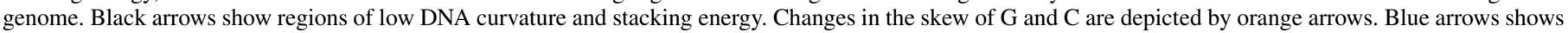

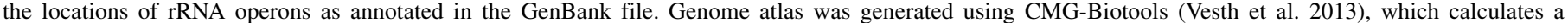
numerical value for each nucleotide and is saved in a file that is read by GeneWiz software. See "Materials and Methods" for details. 
overall estimated coverage of $110 \times$. PGAAP annotation identified 2,792 putative protein-coding sequences. Four $r r n$ operons, 45 transfer RNA (tRNA), 3 noncoding RNA, and 67 pseudogenes are present in the draft genome.

Structural features of a DNA atlas of the NCPPB 2581 genome. A structural DNA atlas was created for the complete genome of $C$. michiganensis subsp. nebraskensis NCPPB 2581 (Fig. 2). The genome atlas shows three categories of data: (i) base composition (AT content, GC skew), (ii) global repeats (direct and inverted), and (iii) DNA structural properties (position preference, DNA stacking energy, and curvature). Genes (blue for leading and red for lagging strand), tRNA, and rRNA are shown as found in the genome annotations. The DNA is used for simple base count information as well as AT content and GC skew. The DNA atlas showed a low AT content consistent with actinomycetales. The GC skew lane (Fig. 2) consists of changes from most $\mathrm{G}$ (blue) to more $\mathrm{C}$ (pink) or vice versa (Fig. 2; orange arrows). Note how the GC skew changes with genes of the leading and lagging strands. There is a $\mathrm{C}$ bias toward the leading strand and $\mathrm{G}$ on the lagging. The genome atlas of $C$. michiganensis subsp. nebraskensis NCPPB 2581 showed no global inverted repeats. Very few direct repeats were observed on the DNA atlas. These corresponded to the location of the three $r r n$ operons (blue arrows). The rrn operons are also located in regions of high intrinsic curvature and stacking energy and low position preference (Fig. 2; brown arrows). Black arrows (Fig. 2) depict regions with low intrinsic curvature and stacking energy and high position preference.

The predicted GI on the complete genome of $C$. michiganensis subsp. nebraskensis NCPPB 2581 in shown in Supplementary Figure S1A. The positions of the GI aligned perfectly with regions of high intrinsic curvature and stacking energy and low position preference (Supplementary Fig. S2, superimposed image). GI predictions are represented as blocks (integrated results in red, IslandPath-DIMOB in blue, and SIGI-HMM in orange) (Supplementary Fig. S1). Circular glyphs within the radial panel indicate putative antimicrobial resistance (green arrows) and virulence (purple arrows) genes. Similar GI were identified for C. michiganensis subsp. nebraskensis DOAB 395 but PAG and AMR were not detected, probably because it is a draft genome of several scaffolds or contigs (Supplementary Fig. S1B). A summary of the GI identified, length, and genes involved is presented in Supplementary Table S1. Genes identified within the GI of $C$. michiganensis subsp. nebraskensis strain NCPPB 2581 (92 genes) and DOAB395 (79 genes) include hypothetical protein or putative excisionase, LD-carboxypeptidase, serine peptidase family S66, and the putative toxin component of a toxin/antitoxin system. The largest GI found on the genome of C. michiganensis subsp. nebraskensis strain NCPPB 2581 is $22.62 \mathrm{~kb}$ while strain DOAB 395 draft genome has a $25.13-\mathrm{kb}$ fragment. The genome of NCPPB 2581 exhibited 6 PAG and 5 AMR, including MFS permease, putative efflux MFS permease, putative multidrug

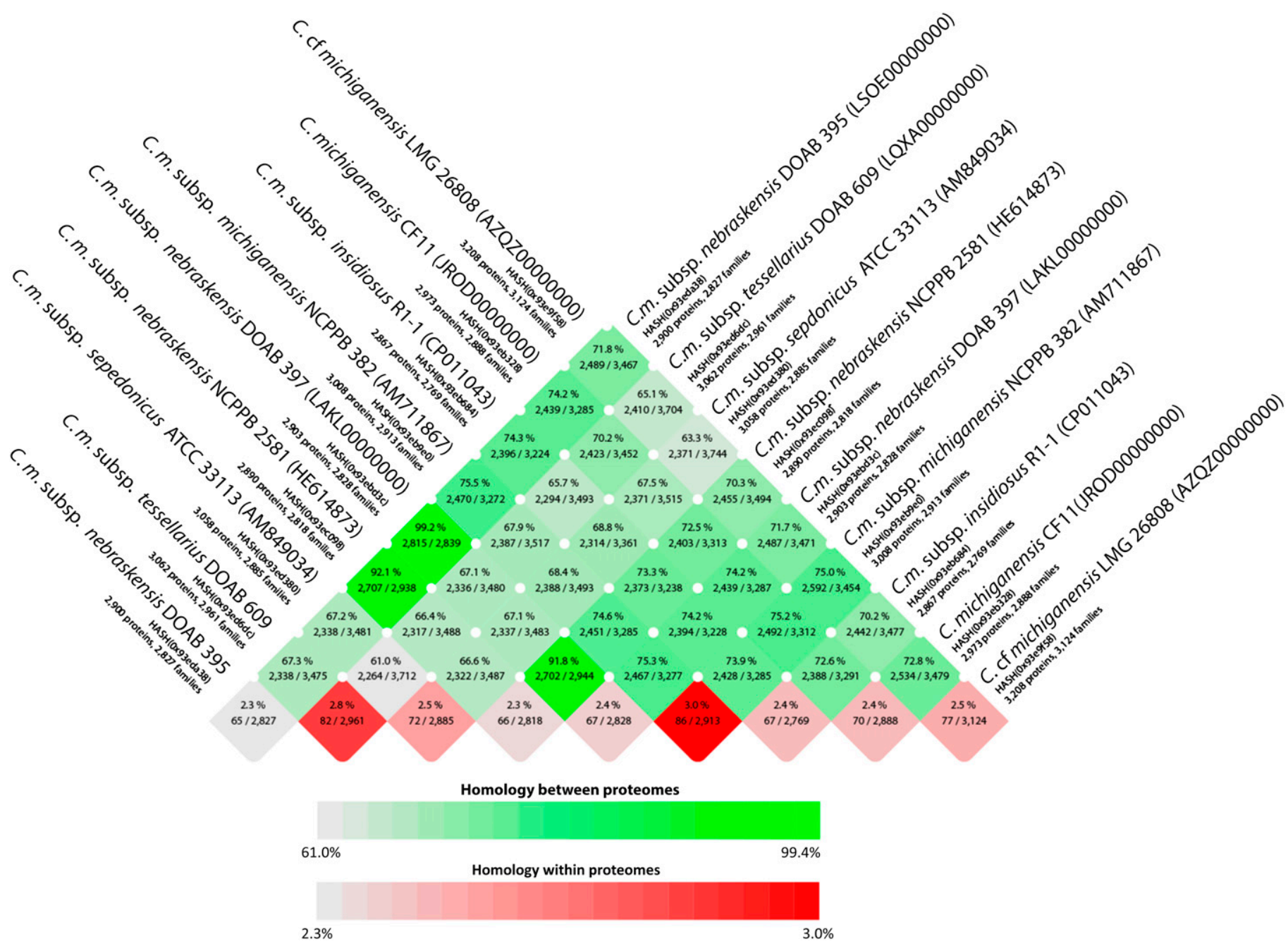

Fig. 3. BLAST matrix of proteomes of nine strains of Clavibacter michiganensis subspecies based on all against-protein comparison with define homologs. A hit is considered significant if a 50 and 50\% (identity and length coverage) requirement between proteomes is met. Paralogs (internal homology) are proteins within a genome matching the same 50-50 rule. Self-matches here are ignored. An XML input file was generated by the program makebmdest and BLAST comparison implemented in CMG-Biotools (Vesth et al. 2013). 
$\mathrm{ABC}$ transporter, fused permease and $\mathrm{ATP}$-binding protein, and $\mathrm{ABC}$ transporter consisting of fused permease and ATPase domains.

Proteome comparisons. The proteomes were constructed with nine genomes. The BLAST matrix illustrates that the conservation between genomes is generally higher within than between subspecies (Fig. 3). The proteomes of $C$. michiganensis subsp. nebraskensis strains DOAB 395 and DOAB 397 exhibited a 99.2\% homology but had 92.1 and $91.8 \%$ homologies, respectively, with type strain NCPPB 2581 (Fig. 3). The majority (99.9\%) of the protein sequences have a 99.6 to $100 \%$ homology between $C$. michiganensis subsp. nebraskensis strains DOAB 395 and DOAB 397 while only four protein sequences $(0.1 \%)$ exhibited a similarity of $<70 \%$. In contrast, $3.0 \%(n=75)$ of the protein sequences of strains DOAB 395 and DOAB 397 showed low homologies $(<70 \%)$ with type strain NCPPB 2581. Proteomes of the three C. michiganensis subsp. nebraskensis strains showed only 67.3 to $75.5 \%$ similarity with the other $C$. michiganensis subspecies (Fig. 3). The genome of $C$. michiganensis subsp. michiganensis NCPPB 382 showed a relatively high similarity $(75.3 \%)$ with the genome of C. michiganensis subsp. nebraskensis DOAB 397 (Fig. 3). The lowest proteome homology of $61.0 \%$ was between $C$. michiganensis subspp. sepedonicus and tessellarius genomes (Fig. 3). The homology within proteomes (Fig. 3, red squares) ranged from 2.3 to $3.0 \%$. C. michiganensis subsp. michiganensis showed the highest paralogous homology within the proteomes. The pan-genomic dendrogram (Fig. 4) confirms the similarities and differences indicated above. The analysis clustered all the $C$. michiganensis subsp. nebraskensis strains in a unique subcluster (Fig. 4). However, strains DOAB 395 and DOAB 397 clustered distinctly from type strain NCPPB 2581 and were well supported by a high bootstrap value (Fig. 4). All the other C. michiganensis subspecies clustered distinctly (Fig. 4).

Validation of TaqMan primers and probes. The primers and probes were analyzed by BLAST to assess their specificity against GenBank entries. The results of a comprehensive BLAST search of sequences for the primers and probe confirmed their specificities. All the primers and probes exhibited a perfect $(100 \%)$ match with the genome of $C$. michiganensis subsp. nebraskensis (HE614873) whereas the other $C$. michiganensis subspecies showed low to no homology with the query nucleotide sequences. For example, the nucleotide sequence of the TaqMan probe cell_cmn38pb had coverage and identity of $100 \%$ (e-value $=0.069$ ) with only the genome of $C$. michiganensis subsp. nebraskensis. The closest sequence hit for the nucleotide sequence of this probe is Exophiala aquamarina CBS 119918 hypothetical protein (XM_013407968), with an $85 \%$ identity (e-value $=4.2$ ). Also, the forward primer cell_cmn3F exhibited $100 \%$ coverage and identity (e-value $=0.04)$ with only the target subspecies (C. michiganensis subsp. nebraskensis). No significant hits were recorded with any of the other $C$. michiganensis subspecies.

Sensitivity and specificity of TaqMan real-time PCR assay. TaqMan real-time PCR performed on serial dilutions of genomic DNA of $C$. michiganensis subsp. nebraskensis NCPPB 2581 exhibited consistent amplification of the respective target genes at the 0.1-pg level (Supplementary Fig. S3) for the primer/ probe combination targeting the secreted cellulase gene $(\mathrm{celB})$ at a fluorescence cut-off value $=0.1$. Primer/probe combinations derived from $50 \mathrm{~S}$ ribosomal protein L36 (rpsJ) showed a similar amplification but at the 1.0-pg level of sensitivity. The cycle threshold $\left(\mathrm{C}_{\mathrm{T}}\right)$ values increased at each dilution, demonstrating the validity of the assay as the target DNA concentration decreased. An increment in $\mathrm{C}_{\mathrm{T}}$ value of 2.1 to 4.3 or 1.3 to 3.8 cycles for celB or $r s p \mathrm{~J}$ probes, respectively, was recorded as the genomic DNA concentration was decreased by 10 -fold. Linear negative correlations between the $\mathrm{C}_{\mathrm{T}}$ values and purified DNA concentration can be established with high $r^{2}$ values of 0.99 and 0.98 for the respective primers/probe combinations.

Eighty-two strains of $C$. michiganensis subsp. nebraskensis isolated between 1969 and 2015 were subjected to TaqMan realtime PCR using the different primer/probe combinations. The base pairing of the probes to the targeted respective gene amplicons confirmed the specificity of detection (Table 1). The increase in fluorescence crossing the threshold values at a specific cycle $\left(C_{T}=19\right.$ to 24) indicated the positive amplification of the targeted gene (Table 1). All C. michiganensis subsp. nebraskensis strains exhibited positive amplification of the expected 107- and 94-bp amplicons for the $c e l \mathrm{~B}$ and rps $\mathrm{J}$ genes, respectively. Agarose gel electrophoresis (data not shown) confirmed the presence of a band of the expected amplicon size. No increase in fluorescence (Table 1) was recorded for 40 bacterial strains consisting of other $C$. michiganensis subspecies and non-Clavibacter spp. using the TaqMan real-time PCR assay (Table 1).

Detection of $C$. michiganensis subsp. nebraskensis in blindtest and naturally infested corn leaf samples. The developed TaqMan real-time PCR was validated in a blind test of growthchamber-inoculated plants (Supplementary Fig. S4) and naturally infested field leaf samples (Table 3). The assay accurately and reliably detected the Goss's wilt pathogen in all three plants that were inoculated in the growth chamber in a blind test of eight plants. The $c e l \mathrm{~B}$ probe assay had a positive detection at $\mathrm{C}_{\mathrm{T}}$ values of 25 to 26 and the probe targeting rps $\mathrm{J}$ gene exhibited $\mathrm{C}_{\mathrm{T}}$ values of 28 to 30 on the same blindly coded samples. Both probes did not show any detectable fluorescence with five samples. The blind samples were decoded by CFIA staff, showing a perfect match to the results obtained using the developed TaqMan assay.

Also, validation of the assay was done using naturally infected corn plants collected in 2014 and 2015. All leaf samples with typical Goss's wilt disease symptoms $(n=17)$ showed detectable fluorescence at $\mathrm{C}_{\mathrm{T}}$ values of 19.6 to 30.4 and 20.7 to 27.8 for $c e l \mathrm{~B}$ and rps J probes, respectively (Table 3 ). The TaqMan detections were validated by colony isolation followed by $16 \mathrm{~S}$ rRNA gene sequencing. Eight leaf samples with noncharacteristic symptoms did not exhibit detectable fluorescence (Table 3). C. michiganensis subsp. nebraskensis strains were not recovered from these samples. Also, no PCR inhibition was detected based on the internal control TaqMan real-time PCR assay (Tambong et al. 2008).

Assay reliability across different real-time PCR platforms. The compatibility of the assay across three widely used real-time PCR platforms was evaluated using the Chromo4 System (MJ Research Bio-Rad Laboratories), LightCycler 480 instrument (Roche), and CFX96 Detection System (Bio-Rad Laboratories). In a multiplex assay, all three platforms showed positive fluorescence detection with the six $C$. michiganensis subsp. nebraskensis strains within the acceptable $C_{T}$ values (Fig. 5). The fluorescence kinetics graphs are shown in Supplementary Figure S4. Strain NCPPB 2581 showed the lowest $\mathrm{C}_{\mathrm{T}}$ values on all the platforms and the means of repeated experiments were comparable (Fig. 5). As expected, the $c e l \mathrm{~B}$ probes showed lower $\mathrm{C}_{\mathrm{T}}$ values compared with the probe targeting the rpsJ gene. None of the other strains of C. michiganensis subspecies or P. stewartii subsp. stewartii exhibited detectable fluorescence.

\section{DISCUSSION}

The reemergence and rapid spread of the Goss's bacterial wilt and blight disease has prompted increased research to better understand the genome organization of this pathogen and develop reliable diagnostic tools. This study reports on the comparative genomics of C. michiganensis subsp. nebraskensis strains isolated in 2014 and the type strain NCPPB 2581 that was isolated over 40 years ago. The data generated expand our knowledge of the $C$. michiganensis subsp. nebraskensis genome organization, which is poorly understood. The results significantly add to the body of information that is required to understand the current reemergence of this phytopathogenic bacterium. Also, the data were exploited to develop a reliable diagnostic tool. The TaqMan assay reported here is robust and comprehensive, including a probe to detect PCR inhibitors. This multiplex assay can process a single sample within $3 \mathrm{~h}$, with a high-throughput capability for rapid and accurate detection of 
C. michiganensis subsp. nebraskensis in 96 samples in less than $16 \mathrm{~h}$. This tool should fill the current gap of a comprehensive diagnostic technique for specific detection and identification of C. michiganensis subsp. nebraskensis in pure cultures and naturally infected corn leaves.

The draft genome size of $C$. michiganensis subsp. nebraskensis DOAB 395 generated in this study is within the range (3.06 to 3.42 $\mathrm{Mb})$ of previously published draft and complete genomes of the
C. michiganensis subspecies (Bentley et al. 2008; Gartemann et al. 2008; Tambong et al. 2015). This indicates that the draft genome of strain DOAB 395 in this study is of good quality (no misassembled fragments), as determined by Quast (Gurevich et al. 2013) and dotplot graph of scaffolds reordering against strain NCPPB 2581.

Both $C$. michiganensis subsp. nebraskensis strains isolated in 2014 show relatively higher pseudogenes. Comparable high levels of nonfunctional genes such as in DOAB 395 and DOAB 397 are

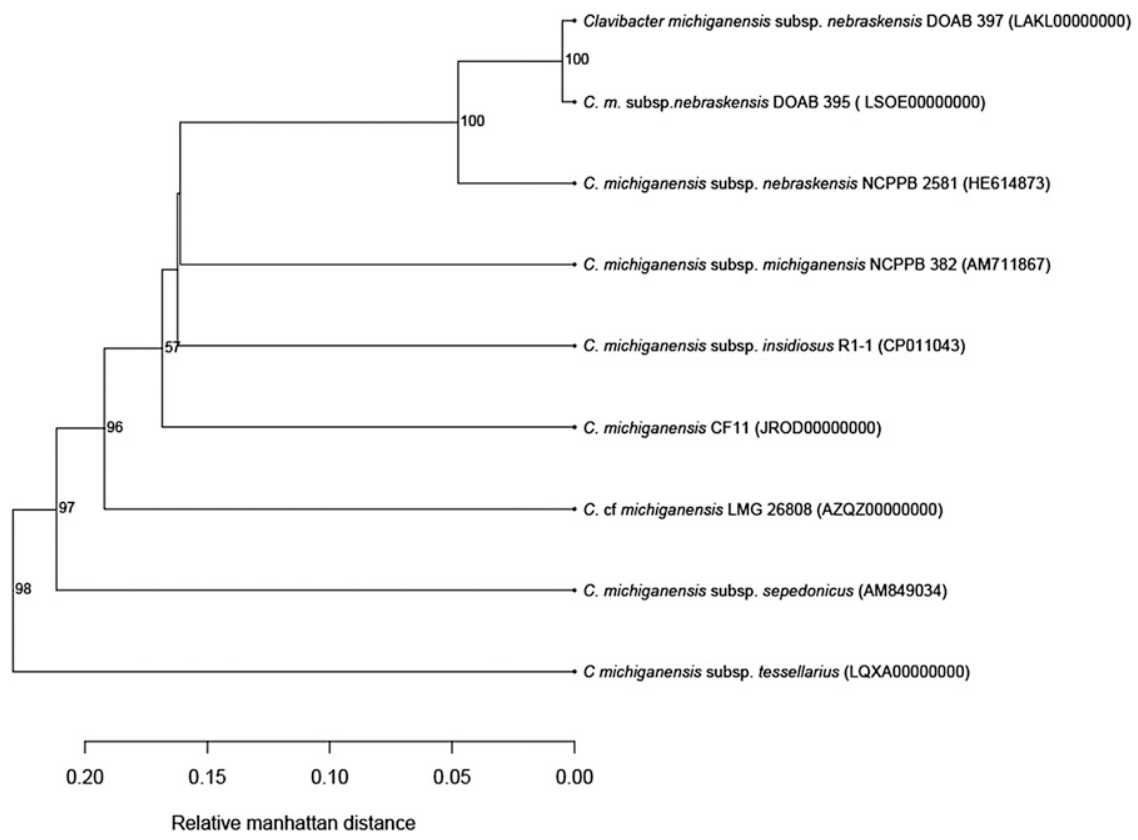

Fig. 4. Pan-genome phylogenetic tree based on shared gene families shows distinct clustering (shaded area) of the Clavibacter michiganensis subsp. nebraskensis strains DOAB 395 and DOAB 397 (isolated in 2014) relative to strain NCPPB 2581 (isolated over 40 years ago). The distinctiveness is supported by high bootstrap values. Bootstrap values $<50 \%$ are not shown. The pan-genome tree was created using the pancoreplot_tree command (Vesth et al. 2013) based on shared gene families.

TABLE 3. Summary of the TaqMan real-time polymerase chain reaction detection of the Goss's wilt pathogen in corn field samples collected in Manitoba, Canada ${ }^{\mathrm{a}}$

\begin{tabular}{|c|c|c|c|c|c|}
\hline \multirow[b]{2}{*}{ Collection ${ }^{\mathrm{b}}$} & \multirow[b]{2}{*}{ Field location } & \multirow[b]{2}{*}{ Date collected } & \multicolumn{2}{|c|}{ Mean $C_{T}$ value $\pm S D$} & \multirow[b]{2}{*}{ Detection } \\
\hline & & & cmn_rpsJ27pb & cell_cmn38pb & \\
\hline Field 6 & West of Emerson & 26 June 2015 & $23.32 \pm 0.91$ & $24.43 \pm 0.78$ & + \\
\hline Field 5 & Alton & 26 June 2015 & $20.57 \pm 0.05$ & $19.6 \pm 0.33$ & + \\
\hline Field 7 & Manitoba & 20 July 2015 & $\mathrm{n} / \mathrm{d}$ & $\mathrm{n} / \mathrm{d}$ & - \\
\hline Field 5 & Manitoba & 20 July 2015 & $23.47 \pm 2.34$ & $23.95 \pm 2.27$ & + \\
\hline Field 8 & South of Roland & 21 July 2015 & $25.27 \pm 2.90$ & $25.68 \pm 1.82$ & + \\
\hline Field 6a & West of Emerson & 21 July 2015 & $24.84 \pm 3.50$ & $25.21 \pm 2.06$ & + \\
\hline Field 1 & Manitoba & 12 August 2015 & $\mathrm{n} / \mathrm{d}$ & $\mathrm{n} / \mathrm{d}$ & - \\
\hline Field 3 & Manitoba & 12 August 2015 & $26.50 \pm 2.81$ & $27.52 \pm 1.42$ & + \\
\hline Field 9 & Lavenham, MB & 17 August 2015 & $25.22 \pm 2.32$ & $24.99 \pm 1.74$ & + \\
\hline Field 9 & Lavenham, MB & 17 August 2015 & $25.77 \pm 0.13$ & $25.72 \pm 0.92$ & + \\
\hline Field 10 & Haywood, MB & 17 August 2015 & $\mathrm{n} / \mathrm{d}$ & $\mathrm{n} / \mathrm{d}$ & - \\
\hline Field 15 & Elm Creek & 12 September 2015 & $22.82 \pm 0.60$ & $21.6 \pm 0.42$ & + \\
\hline Field 16 & Roland S & 12 September 2015 & $24.87 \pm 1.51$ & $23.46 \pm 0.38$ & + \\
\hline Field 17 & Steinbach, MB & 3 September 2015 & $24.84 \pm 0.43$ & $22.60 \pm 0.12$ & + \\
\hline Field 18 & Myrtle, MB & 2 September 2015 & $\mathrm{n} / \mathrm{d}$ & $\mathrm{n} / \mathrm{d}$ & - \\
\hline Field 24 & NE of Gretna, Rhineland & 16 September 2015 & $27.79 \pm 0.18$ & $24.45 \pm 0.26$ & + \\
\hline Field 25 & NE of Emerson, Rhineland & 16 September 2015 & $25.59 \pm 0.16$ & $22.77 \pm 0.03$ & + \\
\hline Field 26 & NE of Alton, Moncalm & 16 September 2015 & $\mathrm{n} / \mathrm{d}$ & $\mathrm{n} / \mathrm{d}$ & - \\
\hline Field 27 & NE of Gretna, Rhineland & 16 September 2015 & $\mathrm{n} / \mathrm{d}$ & $\mathrm{n} / \mathrm{d}$ & - \\
\hline Field 32 & New Bothwell & 29 September 2015 & $27.15 \pm 1.02$ & $23.46 \pm 0.54$ & + \\
\hline Field 33 & West of Steinbach & 29 September 2015 & $25.25 \pm 0.85$ & $23.01 \pm 0.72$ & + \\
\hline Field 35 & Whitemouth & 29 September 2015 & $26.75 \pm 0.78$ & $30.40 \pm 0.26$ & + \\
\hline Field 36 & Whitemouth & 29 September 2015 & $\mathrm{n} / \mathrm{d}$ & $\mathrm{n} / \mathrm{d}$ & - \\
\hline DOAB232 & Greenhouse inoculated & 19 August 2015 & $25.34 \pm 2.12$ & $25.86 \pm 1.74$ & + \\
\hline DOAB232 & Greenhouse inoculated & 29 September 2015 & $26.86 \pm 0.78$ & $21.81 \pm 0.41$ & + \\
\hline
\end{tabular}

a Abbreviations: $\mathrm{C}_{\mathrm{T}}=$ cycle threshold; $\mathrm{SD}=$ standard deviation; $\mathrm{n} / \mathrm{d}=$ no detectable fluorescence; + and - indicate positive and negative, respectively; and $\mathrm{NE}=$ northeast.

${ }^{\mathrm{b}}$ Collection or field number. DOAB232 = DOAB232-inoculated; greenhouse-inoculated positive controls 
often linked with the degeneration of the genome (Bentley et al. 2008). This process is often associated with bacterial species that seem to have recently adapted to a new niche, thus rendering certain genes expendable and genetically selected for their functional removal (Blanc et al. 2007; Parkhill et al. 2001; Tyagi and Saini 2004). Niche adaptation has evolutionary shortcoming that may lead to an increased number of deleterious mutations and size of insertion sequence elements (Bentley et al. 2008). These could lead to reduced selective pressure (Blanc et al. 2007; Nierman et al. 2004; Parkhill et al. 2001).

The low AT observed on the DNA atlas of $C$. michiganensis subsp. nebraskensis strain NCPPB 2581 is characteristic of members of the actinomycetales. The GC skew data shown on the atlas of NCPPB 2581does not distinctively depict the lagging and leading strands as in some other bacterial species. For example, gramnegative bacteria such as Acidaminococcus fermentans strain DSM 20731 (Vesth et al. 2013) and P. ananatis AJ13355 (unpublished data) have distinct GC skew for the lagging and leading strands. The juncture of separation is often considered the origin and terminus of replication (Vesth et al. 2013), with G biased toward the leading strand (Marín and Xia 2008). Contrary to Marín and Xia (2008), this study shows that the $\mathrm{C}$ are biased toward the leading strand. Similar results were observed on DNA atlases of complete genomes of other C. michiganensis subspecies (data not shown).

The atlas of $C$. michiganensis subsp. nebraskensis strain NCPPB 2581also shows varying structural properties on the genome molecule. According to Vesth et al. (2013), the nature of these properties can have significant effects on gene expression and genome rearrangement. Due to differences in base composition, mobile elements can be indicated by regions of different position preference, stacking energy, or intrinsic curvature. For example, the position of the identified GI coincided perfectly with regions of high intrinsic curvature and stacking energy (can easily melt) and low position preference (flexible). Genomic islands (gene clusters potentially from horizontal transfer) are reported to encode a high number of genes involved in important ecological or medical adaptations, including virulence and antimicrobial resistance (Dhillon et al. 2015). In Megasphaera elsdenii and Selenomonas sputigena, these regions are thought to correlate well with high gene expression and are associated with the location of $r r n$ operons (Vesth et al. 2013). In our study, the rRNA genes on the genome of NCPPB 2581 are located within regions of high intrinsic curvature and stacking energy. DNA curvature plays a significant role in many biologically important processes such as transcription initiation (Angermayr et al. 2002; Kozobay-Avraham et al. 2006; Ohyama 2001; Schroth et al. 1992) termination (Hosid and Bolshoy 2004), recombination (Mazin et al. 1994), DNA replication (Ueguchi et al. 1994), and nucleosome positioning (Kiyama and Trifonov 2002).

The BLAST matrix showed a pairwise proteome comparison which identified whether two proteins are shared between genomes (Binnewies et al. 2005). The BLAST matrix indicated that conservation between genomes is generally higher within than among subspecies. The two draft genomes of strains DOAB 395 and DOAB 397 isolated in 2014 exhibited a proteome homology of $99.2 \%$ but had approximately $92 \%$ similarity with that of C. michiganensis subsp. nebraskensis strain NCPPB 2581, the type strain isolated over 40 years ago. This indicates potential differences in genome arrangements between $C$. michiganensis subsp. nebraskensis strains. In Enterobacteriaceae genomes, a 76 to $98.8 \%$ similarity was found between seven genomes of Escherichia coli, with an internal homology of approximately 0.3 to $3 \%$ (Marín and Xia 2008). Also, a study performed on genomes from the Vibrionaceae family showed that different strains of Vibrio cholera share between 70 and $80 \%$ proteins and internal homology ranges from 1.3 to $5.3 \%$ (Vesth et al. 2010). Genome analysis of these two recently isolated $C$. michiganensis subsp. nebraskensis strains (DOAB 395 and DOAB 397) and the type strain (NCPPB 2581) has indicated potential differences given the relatively low homology between the proteomes. Although work is being done to identify these specific differences and determine their significance, we exploited the genome data for the development of a TaqMan real-time PCR tool for rapid detection of $C$. michiganensis subsp. nebraskensis.

Diagnosis of Goss's wilt disease using field inspection for symptoms is insufficient to meet potential plant quarantine requirements. Also, there is no reliable and acceptable enzymelinked immunosorbent assay-based test for detection or

\section{Real-time PCR Platform}

Chromo4
Cy5-labeled cell_cmn38pb probe

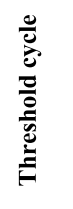

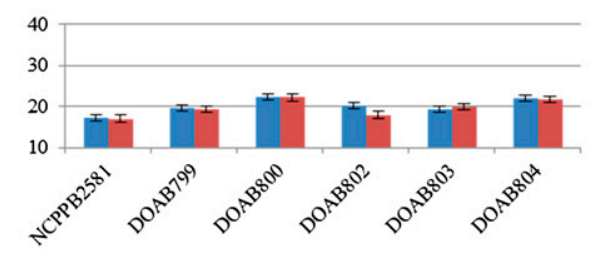
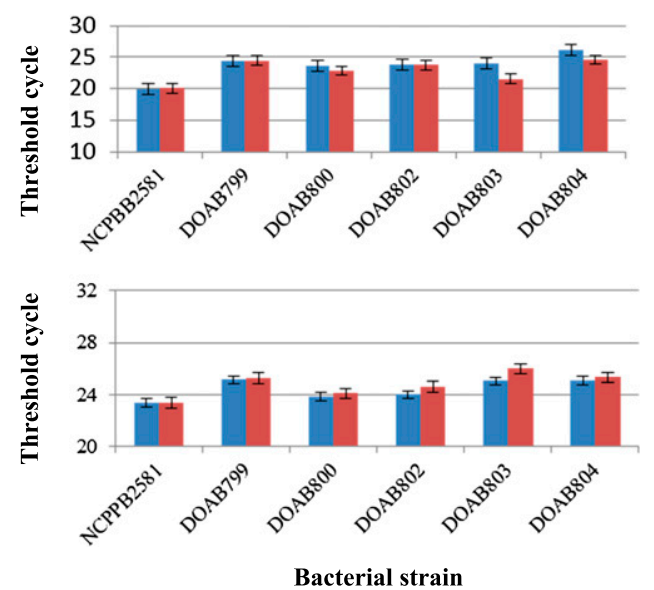

6FAM-labeled cmn rpsJ27pb probe
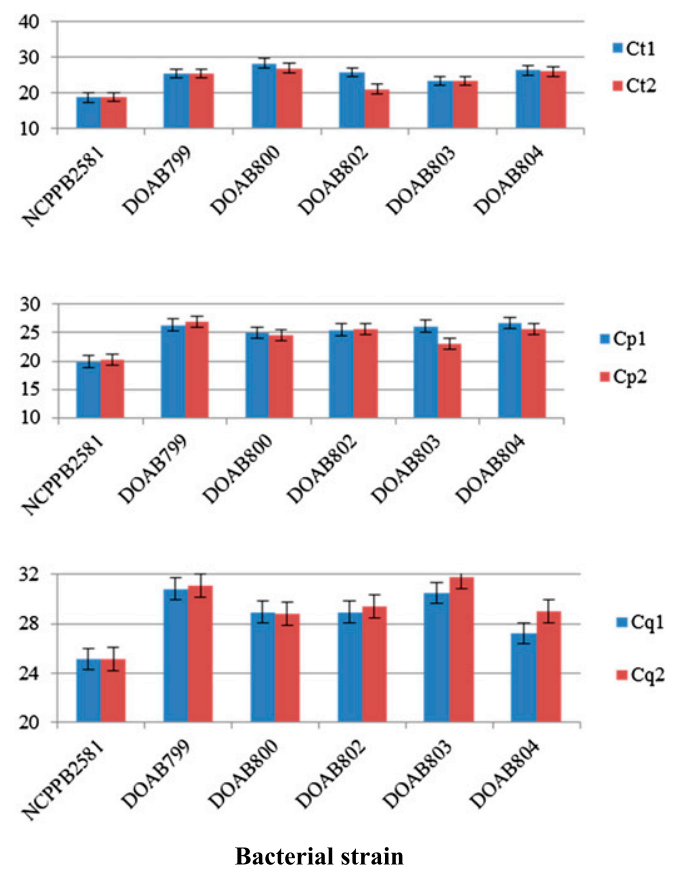

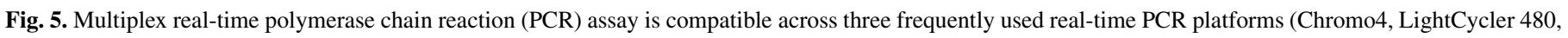
and CFX96). The assay was repeated once, with three replicates per bacterial strain used. 
certification of corn grain shipments. In this study, we have developed the first multiplex TaqMan real-time PCR assay for detection of $C$. michiganensis subsp. nebraskensis in pure cultures and plant leaf samples. TaqMan real-time PCR assays have several advantages over conventional PCR and culture-dependent methods. Because post-PCR processing steps are not required, the assay can be easily automated, leading to high sample throughput (Weller et al. 2000). This, together with the high specificity and sensitivity of the assay, offers significant advantages. Real-time PCR assays have been developed to detect a wide range of bacterial plant pathogens, including $P$. stewartii subsp. stewartii on corn (Tambong et al. 2008), Pseudomonas syringae on tomato (Xu and Tambong 2011), and C. michiganensis subsp. sepedonicus (Schaad et al. 1999) and Ralstonia solanacearum (Weller et al. 2000) in potato tubers. The only publicly available TaqMan real-time PCR assay for detection of $C$. michiganensis subsp. nebraskensis is that of Bach et al. (2003) that was designed to target the 16S-23S ITS regions. This region is known to display intragenomic heterogeneity in some bacteria (Acinas et al. 2004; Gürtler 1999; Liguori et al. 2011; Tambong et al. 2009), partly due to frequent homologous recombination (Gürtler 1999). Regions of DNA molecules that are prone to high recombination are generally not suitable diagnostic markers. The TaqMan real-time PCR assay reported here uses two genes known to exhibit low recombination events. Also, the use of dual TaqMan probes (celB and $r p s \mathrm{~J}$ ) provides an added advantage and high degree of certainty on the specificity and reliability of the assay. A sample (pure culture or infected corn leaf) is reported to be positive for the presence of $C$. michiganensis subsp. nebraskensis only when detectable fluorescence thresholds are achieved with both probes.

Using the optimum TaqMan real-time PCR temperature cycling parameters, the sensitivities ( $0.1 \mathrm{pg}$ for $c e l \mathrm{~B}$ and $1.0 \mathrm{pg}$ for $r p s \mathrm{~J})$ of the assay compared favorably with previously reported real-time PCR assays (Panicker and Bej 2005; Tambong et al. 2008; Xu and Tambong 2011). The celB probe $(0.1 \mathrm{pg})$ exhibited a higher sensitivity compared with the probe $r p s \mathrm{~J}(1 \mathrm{pg})$. The quantum yield of fluorescent dyes attached to nucleotide probes depends on many factors. One of these factors is the fluorescence quenching by adjacent nucleotides (Behlke et al. 2005; Kelley and Barton 1999). This slight difference in sensitivity levels could be attributed to a low quenching effect of cytosine nucleotide on the fluorescence reporter dye (6FAM) at the $5^{\prime}$ end of the $r p s \mathrm{~J}$ probe sequence.

The assay was used successfully to detect the presence of the C. michiganensis subsp. nebraskensis in 17 infected leaf samples. Positive reactions were consistent, suggesting that the process from DNA extraction to detection is reliable. This indicates that the soil DNA kit used to extract total DNA from infected corn leaves produced high-quality DNA with minimal potential PCR inhibitors. This was confirmed using a TaqMan real-time assay derived from $\lambda$ DNA (Tambong et al. 2008) used to demonstrate the presence of PCR inhibitions. Seven leaf samples, however, did not exhibit detectable fluorescence, suggesting that $C$. michiganensis subsp. nebraskensis might not be present. The sample did not indicate the presence of PCR inhibition using the assay mentioned previously. Examination of the leaf samples did not show typical symptoms (characteristic dark "freckles") of the Goss's wilt disease pathogen.

In this study, we sequenced and assembled the draft genome of C. michiganensis subsp. nebraskensis DOAB 395 and performed comparative genomics with previously reported draft genomes of C. michiganensis subsp. nebraskensis strain DOAB 397 (Tambong et al. 2015) and the type strain, NCPPB 2581. Strains DOAB 395 and DOAB 397, isolated in 2014, and strain NCPPB 258, isolated over 40 years ago, seem to show significant genome or proteome differences. Both C. michiganensis subsp. nebraskensis strains isolated in 2014 have a relatively high number of pseudogenes, attributes of potential adaptive ecological significance. Certainly, the genome sequence data of DOAB 395 obtained in this study should provide a better understanding of $C$. michiganensis subsp. nebraskensis and, ultimately, allow for new approaches for rapid identification of strains and taxonomic description of novel subspecies. The genome data were exploited to develop a multiplex TaqMan real-time PCR tool for rapid detection. This tool could bridge the current gap of diagnostic techniques for accurate detection or identification of the Goss's wilt disease pathogen. This procedure is robust and rapid and can be automated with high sample throughput potential, permitting analysis of up to 96 samples within $24 \mathrm{~h}$ of receiving samples. Avoidance of post-PCR gel electrophoresis greatly reduces the opportunity for contamination of the reaction mixtures with target DNA, further increasing the suitability of this assay for routine diagnostic testing. In future work, the assay will be adapted, optimized, and validated for detection of $C$. michiganensis subsp. nebraskensis in corn seed or grain destined for export. The assay would be useful domestically as well to monitor disease and variability of the pathogen with time and location.

\section{ACKNOWLEDGMENTS}

This study was funded by Agriculture and Agri-Food Canada through projects J-000409 and J-000985, and by Manitoba Corn Growers Association project number CRADA AGR-10755. We thank the staff of GénomeQuébec, McGill University, Montreal, Canada, for technical assistance with the sequencing of the C. michiganensis subsp. nebraskensis DOAB 395, and all of the summer students who worked on these projects.

\section{LITERATURE CITED}

Acinas, S. G., Marcelino, L. A., Klepac-Ceraj, V., and Polz, M. F. 2004. Divergence and redundancy of $16 \mathrm{~S}$ rRNA sequences in genomes with multiple $r r n$ operons. J. Bacteriol. 186:2629-2635.

Agarkova, I. V., Lambrecht, P. A., and Vidaver, A. K. 2011. Genetic diversity and population structure of Clavibacter michiganensis subsp. nebraskensis. Can. J. Microbiol. 57:366-374.

Ahmad, A., Mbofung, G. Y., Acharya, J., Schmidt, C. L., and Robertson, A. E. 2015. Characterization and comparison of Clavibacter michiganensis subsp. nebraskensis strains recovered from epiphytic and symptomatic infections of maize in Iowa. PLoS One 10:e0143553.

Andrews, S. 2015. FastQC: A quality-control tool for high-throughput sequence data. Online publication. http://www.bioinformatics.babraham.ac. uk/projects/fastqc

Angermayr, M., Oechsner, U., Gregor, K., Schroth, G. P., and Bandlow, W. 2002. Transcription initiation in vivo without classical transactivators: DNA kinks flanking the core promoter of the housekeeping yeast adenylate kinase gene, AKY2, position nucleosomes and constitutively activate transcription. Nucleic Acids Res. 30:4199-4207.

Angiuoli, S.V., Gussman, A., Klimke, W., Cochrane, G., Field, D., Garrity, G., Kodira, C. D., Kyrpides, N., Madupu, R., Markowitz, V., Tatusova, T., Thomson, N., and White, O. 2008. Toward an online repository of Standard Operating Procedures (SOPs) for (meta)genomic annotation. Omics 12: 137-141.

Anonymous. 2005. PM 7/42 Clavibacter michiganensis subsp. michiganensis. Bull. OEPP/EPPO Bull. 43:46-67.

Bach, H. J., Jessen, I., Schloter, M., and Munch, J. C. 2003. A TaqMan-PCR protocol for quantification and differentiation of the phytopathogenic Clavibacter michiganensis subspecies. J. Microbiol. Methods 52:85-91.

Behlke, M. A., Huang, L., Bogh, L., Rose, S., and Devor, E. J. 2005. Fluorescence Quenching by Proximal G-bases. Analytical Services Integrated DNA Technologies. https://www.idtdna.com/pages/docs/technical-reports/ fluorescence-quenching-by-proximal-g-bases.pdf?sfvrsn=6

Benson, D. A., Karsch-Mizrachi, I., Clark, K., Lipman, D. J., Ostell, J., and Sayers, E. W. 2012. GenBank. Nucleic Acids Res. 40:D48-D53.

Bentley, S. D., Corton, C., Brown, S. E., Barron, A., Clark, L., Doggett, J., Harris, B., Ormond, D., Quail, M. A., May, G., Francis, D., Knudson, D., Parkhill, J., and Ishimaru, C. A. 2008. Genome of the actinomycete plant pathogen Clavibacter michiganensis subsp. sepedonicus suggests recent niche adaptation. J. Bacteriol. 190:2150-2160.

Binnewies, T. T., Hallin, P. F., Staerfeldt, H. H., and Ussery, D. W. 2005. Genome Update: Proteome comparisons. Microbiology 151:1-4.

Blanc, G., Ogata, H., Robert, C., Audic, S., Suhre, K., Vestris, G., Claverie, J. M., and Raoult, D. 2007. Reductive genome evolution from the mother of Rickettsia. PLoS Genet. 3:e14.

Bolshoy, A., McNamara, P., Harrington, R. E., and Trifonov, E. N. 1991. Curved DNA without A-A: Experimental estimation of all 16 DNA wedge angles. Proc. Natl. Acad. Sci. USA 88:2312-2316. 
Davis, M. J., Gillaspie, A. G., Vidaver, A. K., and Harris, R. 1984. Clavibacter: A new genus containing some phytopathogenic coryneform bacteria, including Clavibacter xyli subsp. xyli sp. nov., and Clavibacter xyli subsp. cynodontis subsp. nov., pathogens that cause ratoon stunting of sugarcane and Bermuda grass stunting disease. Int. J. Syst. Bacteriol. 34:107-117.

Dawson, A. 2010. Goss's wilt widespread in Manitoba corn. Online publication. http://www.manitobacooperator.ca/2010/09/16/gosss-wilt-widespreadin-manitoba-corn-for-sep-16-2010/

Dhillon, B. K., Laird, M. R., Shay, J. A., Winsor, G. L., Lo, R., Nizam, F., Pereira, S. K., Waglechner, N., McArthur, A. G., Langile, M. G. I., and Brinkman, F. S. I. 2015. IslandViewer 3: More flexible, interactive genomic island discovery, visualization and analysis. Nucleic Acids Res. 43:W104W108.

Eichenlaub, R., Gartemann, K.-H., and Burger, A. 2006. Clavibacter michiganensis, a group of gram-positive phytopathogenic bacteria. Pages 385-422 in: Plant-Associated Bacteria. S. S. Gnanamanickam, ed. Springer, Dordrecht, The Netherlands.

Feng, L.-P., Yu, D.-D., Wang, Y.-C., Wu, C.-P., Wu, X.-H., Zhang, J.-X., Wang, J., and Song, T. 2014. Nested-PCR detection of Clavibacter michiganensis subsp. nebraskensis. Chin. J. Food Saf. Qual. 25:3933-3938.

Gartemann, K. H., Abt, B., Bekel, T., Burger, A., Engemann, J., Flugel, M., Gaigalat, L., Goesmann, A., Gräfen, I., Kalinowski, J., Kaup, O., Kirchner, O., Krause, L., Linke, B., McHardy, A., Meyer, F., Pohle, S., Rückert, C., Schneiker, S., Zellermann, E.-M., Pühler, A., Eichenlaub, R., Kaiser, O., and Bartels, D. 2008. The genome sequence of the tomato-pathogenic actinomycete Clavibacter michiganensis subsp. michiganensis NCPPB382 reveals a large island involved in pathogenicity. J. Bacteriol. 190:2138-2149.

Gross, D. C., and Vidaver, A. K. 1978. A selective medium for isolation of Corynebacterium nebraskense from soil and plant parts. Phytopathology 69:82-87.

Gurevich, A., Saveliev, V., Vyahhi, N., and Tesler, G. 2013. QUAST: Quality assessment tool for genome assemblies. Bioinformatics 29:1072-1075.

Gürtler, V. 1999. The role of recombination and mutation in 16S-23S rDNA spacer rearrangements. Gene 238:241-252.

Heppner, K. 2010. Goss's wilt in corn. Online publication. PortageOnline. http://www.portageonline.com/component/content/archive/2010/8

Ho Sui, S. J., Fedynak, A., Hsiao, W. W., Langille, M. G., and Brinkman, F. S. 2009. The association of virulence factors with genomic islands. PLoS One 4:e8094

Hosid, S., and Bolshoy, A. 2004. New elements of the termination of transcription in prokaryotes. J. Biomol. Struct. Dyn. 22:347-354.

Hyatt, D., Chen, G. L., Locascio, P. F., Land, M. L., Larimer, F. W., and Hauser, L. J. 2010. Prodigal: Prokaryotic gene recognition and translation initiation site identification. BMC Bioinf. 11:119.

Jackson, T. A., Harveson, R. M., and Vidaver, A. K. 2007. Reemergence of Goss's wilt and blight of corn to the central High Plains. Online publication. Plant Health Prog. doi:10.1094/PHP-2007-0919-01-BR

Jacques, M. A., Durand, K., Orgeur, G., Balidas, S., Fricot, C., Bonneau, S., Quillévéré, A., Audusseau, C., Olivier, V., Grimault, V., and Mathis, R. 2012. Phylogenetic analysis and polyphasic characterization of Clavibacter michiganensis strains isolated from tomato seeds reveal that nonpathogenic strains are distinct from C. michiganensis subsp. michiganensis. Appl. Environ. Microbiol. 78:8388-8402.

Jensen, L. J., and Knudsen, S. 2000. Automatic discovery of regulatory patterns in promoter regions based on whole cell expression data and functional annotation. Bioinformatics 16:326-333.

Kelley, S. O., and Barton, J. K. 1999. Electron transfer between bases in double helical DNA. Science 283:375-381.

Kiyama, R., and Trifonov, E. N. 2002. What positions nucleosomes? A model. FEBS Lett. 523:7-11.

Kozobay-Avraham, L., Hosid, S., and Bolshoy, A. 2006. Involvement of DNA curvature in intergenic regions of prokaryotes. Nucleic Acids Res. 34: 2316-2327.

Lane, L. D. 1991. 16S/23S rRNA sequencing. Pages 115-175 in: Nucleic Acid Techniques in Bacterial Systematics. E. Stackebrandt and M. Goodfellow, eds. John Wiley \& Sons, Ltd., Chichester, England.

Liguori, A. P., Warrington, S. D., Ginther, J. L., Pearson, T., Bowers, J., Glass, M. B., Mayo, M., Wuthiekanun, V., Engelthaler, D., Peacock, S. J., Currie, B. J., Wagner, D. M., Keim, P., and Tuanyok, A. 2011. Diversity of 16S-23S rDNA internal transcribed spacer (ITS) reveals phylogenetic relationships in Burkholderia pseudomallei and its near-neighbors. PLoS One 6:e29323.

Lobry, J. R. 1996. Asymmetric substitution patterns in the two DNA strands of bacteria. Mol. Biol. Evol. 13:660-665.

Lu, C. L., Chen, K.-T., Huang, S.-Y., and Chiu, H.-T. 2014. CAR: Contig assembly of prokaryotic draft genomes using rearrangements. BMC Bioinf. 15:381.

Malvick, D., Syverson, R., Mollov, D., and Ishimaru, C. A. 2010. Goss's bacterial blight and wilt of corn caused by Clavibacter michiganensis subsp. nebraskensis occurs in Minnesota. Plant Dis. 94:1064.
Marín, A., and Xia, X. 2008. GC skew in protein-coding genes between the leading and lagging strands in bacterial genomes: New substitution models incorporating strand bias. J. Theor. Biol. 253:508-513.

Mazin, A., Milot, E., Devoret, R., and Chartrand, P. 1994. KIN17, a mouse nuclear protein, binds to bent DNA fragments that are found at illegitimate recombination junctions in mammalian cells. Mol. Gen. Genet. 244: 435-438.

McArthur, A. G., Waglechner, N., Nizam, F., Yan, A., Azad, M. A., Baylay, A. J., Bhullar, K., Canova, M. J., De Pascale, G., Ejim, L., Kalan, L., King, A. M., Koteva, K., Morar, M., Mulvey, M. R., O’Brien, J. S., Pawlowski, A. C., Piddock, L. J. V., Spanogiannopoulos, P., Sutherland, A. D., Tang, I., Taylor, P. L., Thaker, M., Wang, W., Yan, M., Yu, T., and Wright, G. D. 2013. The comprehensive antibiotic resistance database. Antimicrob. Agents Chemother. 57:3348-3357.

Nierman, W. C., DeShazer, D., Kim, H. S., Tettelin, H., Nelson, K. E., Feldblyum, T., Ulrich, R. L., Ronning, C. M., Brinkac, L. M., Daugherty, S. C., Davidsen, T. D., Deboy, R. T., Dimitrov, G., Dodson, R. J., Durkin, A. S., Gwinn, M. L., Haft, D. H., Khouri, H., Kolonay, J. F., Madupu, R., Mohammoud, Y., Nelson, W. C., Radune, D., Romero, C. M., Sarria, S., Selengut, J., Shamblin, C., Sullivan, S. A., White, O., Yu, Y., Zafar, N., Zhou, L., and Fraser, C. M. 2004. Structural flexibility in the Burkholderia mallei genome. Proc. Natl. Acad. Sci. USA 101:14246-14251.

Ohyama, T. 2001. Intrinsic DNA bends: An organizer of local chromatin structure for transcription. BioEssays 23:708-715.

Orlando, C., Pinzani, P., and Pazzagli, M. 1998. Developments in quantitative PCR. Clin. Chem. Lab. Med. 36:255-269.

Ornstein, R. L., and Rein, R. 1978. An optimized potential function for the calculation of nucleic acid interaction energies I. base stacking. Biopolymers 17:2341-2360.

Panicker, G., and Bej, A. K. 2005. Real-time PCR detection of Vibrio vulnificus in oysters: Comparison of oligonucleotide primers and probes targeting vvhA. Appl. Environ. Microbiol. 71:5702-5709.

Parkhill, J., Wren, B. W., Thomson, N. R., Titball, R. W., Holden, M. T., Prentice, M. B., Sebaihia, M., James, K. D., Churcher, C., Mungall, K. L., Baker, S., Basham, D., Bentley, S. D., Brooks, K., Cerdeño-Tárraga, A. M., Chillingworth, T., Cronin, A., Davies, R. M., Davis, P., Dougan, G., Feltwell, T., Hamlin, N., Holroyd, S., Jagels, K., Karlyshev, A. V., Leather, S., Moule, S., Oyston, P. C. F., Quail, M., Rutherford, K., Simmonds, M., Skelton, J., Stevens, K., Whitehead, S., and Barrell, B. G. 2001. Genome sequence of Yersinia pestis, the causative agent of plague. Nature 413: 523-527.

Paul, V. H., and Smith, I. M. 1989. Bacterial pathogens of Gramineae: Systematic review and assessment of quarantine status for the EPPO region. Bull. OEPP/EPPO. Bull. 19:33-42.

Ruhl, G., Wise, K., Creswell, T., Leonberger, A., and Speers, C. 2009. First report of Goss's bacterial wilt and leaf blight on corn caused by Clavibacter michiganensis subsp. nebraskensis in Indiana. Plant Dis. 93:841.

Schaad, N. W., Berthier, S. Y., Sechler, A., and Knorr, D. 1999. Detection of Clavibacter michiganensis subsp. sepedonicus in potato tubers by BIO-PCR and an automated real-time fluorescence detection system. Plant Dis. 83: 1095-1100.

Schroth, G. P., Siino, J. S., Cooney, C. A., Th'ng, J. P., Ho, P. S., and Bradbury, E. M. 1992. Intrinsically bent DNA flanks both sides of an RNA polymerase I transcription start site. Both regions display novel electrophoretic mobility. J. Biol. Chem. 26:9958-9964.

Shpigelman, E. S., Trifonov, E. N., and Bolshoy, A. 1993. CURVATURE: Software for the analysis of curved DNA. Comput. Appl. Biosci. 9:435-440.

Simpson, J. T., Wong, K., Jackman, S. D., Schein, J. E., Jones, S. J., and Birol, I. 2009. ABySS: A parallel assembler for short read sequence data. Genome Res. 19:1117-1123.

Smid, E. J., Hausen, A. H. J., and Gorris, L. G. M. 1995. Detection of Erwinia carotovora subsp. atroseptica and Erwinia chrysanthemi in potato tubers using polymerase chain reaction. Plant Pathol. 44:1058-1069.

Tambong, J. T., de Cock, A. W., Tinker, N. A., and Levesque, C. A. 2006. Oligonucleotide array for identification and detection of Pythium species. Appl. Environ. Microbiol. 72:2691-2706.

Tambong, J. T., Mwange, K. N., Bergeron, M., Ding, T., Mandy, F., Reid, L. M., and Zhu, X. 2008. Rapid detection and identification of the bacterium Pantoea stewartii in maize by TaqMan real-time PCR assay targeting the cpsD gene. J. Appl. Microbiol. 104:1525-1537.

Tambong, J. T., Xu, R., Adam, Z., Cott, M., Rose, K., Reid, L. M., Daayf, F., Brière, S., and Bilodeau, G. J. 2015. Draft Genome sequence of Clavibacter michiganensis subsp. nebraskensis strain DOAB 397, isolated from an infected field corn plant in Manitoba, Canada. Genome Announc. 3:e00768-15.

Tambong, J. T., Xu, R., and Bromfield, E. P. S. 2009. Intercistronic heterogeneity of the 16S-23S rRNA spacer region among Pseudomonas strains isolated from subterranean seeds of hog peanut (Amphicarpa bracteata). Microbiology 155:2630-2640. 
Tyagi, J. S., and Saini, D. K. 2004. Did the loss of two-component systems initiate pseudogene accumulation in Mycobacterium leprae? Microbiology 150:4-7.

Ueguchi, C., Kakeda, M., Yamada, H., and Mizuno, T. 1994. An analogue of the DnaJ molecular chaperone in Escherichia coli. Proc. Natl. Acad. Sci. USA 91:1054-1058.

Vesth, T., Lagesen, K., Acar, O., and Ussery, D. W. 2013. CMG-biotools, a free workbench for basic comparative microbial genomics. PLoS One 8: e60120.

Vesth, T., Wassenaar, T. M., Hallin, P. F., Snipen, L., Lagesen, K., and Ussery, D. W. 2010. On the origins of a Vibrio species. Microb. Ecol. 59:1-13.

Vidaver, A. K., Gross, D. C., Wysong, D. S., and Doupnik, J. R. 1981. Diversity of Corynebacterium nebraskense strains causing Goss's bacterial wilt and blight of corn. Plant Dis. 65:480-483.

Waleron, M., Waleron, K., Kamasa, J., Przewodowski, W., and Lojkowska, E. 2011. Polymorphism analysis of house-keeping genes for identification and differentiation of Clavibacter michiganensis subspecies. Eur. J. Plant Pathol. 131:341-354.

Weller, S. A., Elphinstone, J. G., Smith, N. C., Boonham, N., and Stead, D. E. 2000. Detection of Ralstonia solanacearum strains with a quantitative, multiplex, real-time, fluorogenic PCR (TaqMan) assay. Appl. Environ. Microbiol. 66:2853-2858.

Worning, P., Jensen, L. J., Hallin, P. F., Staerfeldt, H. H., and Ussery, D. W. 2006. Origin of replication in circular prokaryotic chromosomes. Environ. Microbiol. 8:353-361.

$\mathrm{Xu}, \mathrm{R}$, and Tambong, J. T. 2011. A TaqMan real-time PCR assay targeting the cytochrome o ubiquinol oxidase subunit II gene for detection of several pathovars of Pseudomonas syringae. Can. J. Plant Pathol. 33:318-331.

Yasuhara-Bell, J., de Silva, A., Heuchelin, S. A., Chaky, J. L., and Alvarez, A. M. 2016. Detection of Goss's wilt pathogen Clavibacter michiganensis subsp. nebraskensis in maize by loop-mediated amplification. Phytopathology 106:226-235. 